\title{
LAS ÁREAS PROTEGIDAS COMO TERRITORIOS TURÍSTICOS: ANÁLISIS CRÍTICO A PARTIR DEL CASO DE LOS PARQUES NATURALES DE LA SIERRA MORENA ANDALUZA
}

\author{
Rafael Garzón García \\ María Luisa Ramírez López \\ Universidad de Córdoba
}

\section{RESUMEN}

El artículo trata de ofrecer una aproximación rigurosa y crítica a la compleja cuestión de la relación entre turismo y áreas naturales de singular cualificación, con especial énfasis en aquellas protegidas bajo la figura de Parque Natural, teóricamente marcada por su especial idoneidad para el desarrollo turístico a tenor de su flexibilidad y polifuncionalidad. El estudio, aplicado al ámbito de la Sierra Morena andaluza, aborda aspectos claves tales como la necesaria consideración de la base territorial de las áreas protegidas, la operatividad de los instrumentos para el fomento turístico, la deseable vinculación con el uso público y, sobre todo, la necesaria definición de una estrategia turística específica para los parques. Morena.

Palabras clave: Turismo; uso público; parque; planificación; desarrollo rural; Sierra

\section{Protected areas as tourist areas: a critical analysis based on the case of Andalusian Sierra Morena Nature Parks}

\section{ABSTRACT}

The article seeks to provide a rigorous and critical approach to the complex issue of the relationship between tourism and quality natural areas, focused on those protected under the figure of Nature Park, defined by its special suitability for tourism development

Recibido: 21 de octubre de 2016

Devuelto para su revisión: 6 de febrero de 2017

Aceptado: 20 de marzo de 2017

Departamento de Geografía y Ciencias del Territorio. Universidad de Córdoba. Plaza del Cardenal Salazar 3. 14003 CÓRDOBA (España).E-mail: rafael.garzon@uco.es; mluisa.ramirez@uco.es 
according to its flexibility and multifunctionality. The study, applied to the Andalusian Sierra Morena range, addresses key issues such the necessary consideration of the territorial base of protected areas, the instruments for tourism promotion, the link between tourism and public use, and, above all, the need of defining a specific tourism strategy for parks.

Keywords: Tourism; public use; park; planning; rural development; Sierra Morena.

\section{EL COMPLEJO ACERCAMIENTO A LA CUESTIÓN TURÍSTICA EN LOS ESPACIOS RURALES/NATURALES DE CALIDAD}

Se asiste -de unas décadas a esta parte- a un fenómeno novedoso en el marco de las actuales sociedades fuertemente urbanizadas. Nos referimos a la creciente afluencia de visitantes en espacios rurales y/o naturales de calidad, muchos de ellos sometidos por ello a un régimen de protección legal, conformándose como espacios o áreas protegidas. Dicha afluencia asume en la actualidad dos formas básicas, en estrecha relación entre sí: una oferta de uso público, junto a una experiencia específicamente turística, lo que nos sitúa en el contexto del análisis planteado en este trabajo.

El uso público se identifica con aquellos servicios, actividades y equipamientos provistos en los espacios naturales (protegidos), con el objetivo de facilitar su disfrute, conocimiento, interpretación y/o valoración, y cuya provisión se garantiza por parte de las instancias administrativas responsables de la ordenación y gestión de tales espacios (Hernández y Gómez-Limón, 2005). Pese a la evidente proximidad conceptual con el turismo, debe en todo caso remarcarse -como es bien conocido- el carácter de éste en tanto que sector con una entidad propia y diferenciada, con una recurrente proyección económica, recreativa y de no habitualidad (Jáimez, 2004), aspectos todos ellos no necesariamente vinculados a la actividad del uso público. Así pues, el turismo, pese a lo amplio y diverso de la actividad, no engloba al uso público (algunos de cuyos condicionantes desbordan lo propio y específico de la actividad turística), si bien la experiencia turística en espacios rurales y/o naturales puede hacer uso de las infraestructuras y servicios de uso público, configurándose éste en determinados casos como una parte esencial de dicha experiencia turística más amplia. Qué duda cabe, en relación con ello, que los espacios protegidos en general -y más en particular aquellas categorías de protección más flexibles y con una vocación de multifuncionalidad, sobre todo los Parques $^{1}$ - comenzaron a percibirse como un escenario privilegiado para el desarrollo de novedosas modalidades turísticas (Cals y Riera, 1989).

En efecto, ya desde las décadas de los ochenta y noventa del pasado siglo se constató con nitidez el proceso de reforzamiento de la funcionalidad turística de numerosos espacios rurales y naturales españoles, siendo no pocos los ámbitos en que el turismo se ha venido percibiendo como un sector económico emergente y de importantes expectativas, un pilar de primer orden para la revitalización de las economías locales (Troitiño, 1995; VV.AA., 2008).

1 Categoría reconocida como tal en la legislación española de áreas protegidas: primeramente en la Ley 4/1989, de 27 de marzo, de Conservación de los Espacios Naturales y la Flora y Fauna Silvestres, y más recientemente en la Ley 42/2007, de 13 de diciembre del Patrimonio Natural y la Biodiversidad (art. 30). 
De esta percepción se ha derivado, sin embargo, uno de los principales aspectos de conflictividad asociados al nuevo proceso de funcionalización turística: la asignación de un cierto carácter redentorista a la actividad, concretado en la visión del turismo como sustitutivo -en buena medida- de las actividades primarias en el contexto socioeconómico de zonas rurales de especial encanto o belleza pero en situación de crisis o pérdida de rentabilidad de sus aprovechamientos agrarios tradicionales (Troitiño, 1995; Sánchez, 2001). Se trata de una percepción -identificable con la de un monocultivo turístico- crecientemente generalizada en numerosos ámbitos rurales españoles durante los últimos lustros, pese a lo cual no se ha hallado exenta de importantes riesgos e implicaciones poco deseables.

Entre ellas se ha remarcado muy especialmente el que las actividades agrarias no pueden ser abandonadas ni tan siquiera postergadas, por el simple hecho de que se conforman como el principal elemento definidor y sustentador de las formas de vida y paisajes ligados a las propias comunidades rurales, situándose por ello "en la base de las restantes alternativas de desarrollo con que cuentan estos espacios" (Silva, 1994, 449). Pero junto a ello se destaca asimismo el excesivo desarrollo cuantitativo en materia turística, mostrando de manera recurrente un crecimiento poco controlado, manifestándose en la mayor parte de los casos como un auténtico cajón de sastre, con motivaciones de lo más variopinto, donde se ha adolecido por lo general de un excesivo énfasis alojativo, acompañado en ocasiones de intereses inmobiliarios e incluso de un cierto componente de ilegalidad. El resultado más frecuente ha sido la generación de efectos contraproducentes sobre el espacio, al margen de una específica connotación medioambiental y/o patrimonial² (Gómez-Limón, 1993; Sánchez, 2001; Martínez, 2004), lo que ha venido teniendo como consecuencia la creciente desvirtuación del modelo de turismo rural/natural emanado de la década de los noventa (Grande, 2006).

Resulta clave a este respecto la necesidad de ponderar adecuadamente las posibilidades de desarrollo turístico, en función de los condicionantes territoriales. La actividad turística debe contemplarse como una alternativa más en un contexto de necesaria diversificación socioeconómica, y, en caso de optarse por ella, habría de ser objeto de una rigurosa consideración de tales posibilidades de desarrollo efectivo.

El carácter imperativo de un adecuado dimensionamiento del fenómeno turístico (en sentido tanto positivo como preventivo) se torna absolutamente justificable en el caso del turismo de base rural y natural (y muy especialmente en espacios de singular cualificación), al tratarse de modalidades de particulares condicionantes - corta duración de las estancias, bajos índices de repetición de las visitas, carácter selectivo y de pequeña escala-, por lo que difícilmente pueden contemplarse -en términos generales y desde la perspectiva de los agentes locales- como actividades exclusivas sino más bien como complementarias de las actividades (agrarias) tradicionales (Grande, 2006).

2 Especialmente elocuente en este sentido resulta el siguiente fragmento, extraído de uno de los primeros Informes de Medio Ambiente elaborados desde la Administración ambiental andaluza: "Uno de los rasgos que definen el turismo de naturaleza es precisamente su no masificación, por lo que las ofertas turísticas han de buscar implantaciones de baja densidad, a la vez que los ecosistemas y enclaves más sensibles deben ser preservados de una excesiva presión de visitantes y usuarios. La demanda de actividades de turismo de naturaleza puede llegar a provocar este tipo de problemas, que ya se han empezado a detectar en zonas de los parques naturales de Sierra Nevada, Sierra de Cazorla, Segura y Las Villas, y Sierra de Grazalema" (Consejería de Cultura y Medio Ambiente, 1993, 6-7). 
A este respecto, hoy resulta en gran medida generalizada la convicción de que el modelo de turismo en espacios rurales/naturales de calidad ha de basarse - de manera general y como requisito ineludible - en la consideración y valorización selectivas de los caracteres de calidad y diferenciación de cada territorio. El desarrollo turístico ha de pasar por una potenciación de aquella oferta que hiciese verdadero uso de las oportunidades ofrecidas por los recursos de las zonas concernidas, tanto de carácter cultural -sobre la base del patrimonio rural, en sentido amplio- como natural (Crosby y Morena, 1993; Grande, 2006; Cànoves et al., 2006; Villarino et al., 2009). La justificación de ello cabe situarla en la concepción -crecientemente asumida, tanto en estudios turísticos como entre agentes territoriales- de que la capacidad de atracción de un territorio viene dada más por la oferta de recursos y actividades -la tradicionalmente denominada como oferta complementaria ${ }^{3}-$, que por el propio alojamiento y su cualificación. Se otorga, pues, un peso creciente al elemento propio y distintivo de cada territorio y a la experiencia turística asociada al mismo, a lo que se subordinaría la búsqueda -ulterior- del alojamiento en función de ello.

En ese nuevo contexto, los espacios naturales protegidos podrían desempeñar un papel de primer orden, a tenor tanto de su especial cualificación como de la propia dotación de un régimen protector, que, además de configurarlos como sujetos de una ordenación y gestión específicas, los define como realidades geográficas bien reconocibles en la matriz territorial (Ceballos-Lascuraín, 1996).

A este respecto, y desde una perspectiva más específica y operativa, se han planteado algunas propuestas de interés (Marchena, 1995; Ceballos-Lascurain, 1996; Eagles et al., 2002; Bázquez, 2002; Yunis, 2006; Antón et al., 2008; Vacas, 2010; López, ed., 2010) respecto de la funcionalización turística de los espacios protegidos en función de sus condicionantes territoriales y de gestión. En la Figura 1 se aporta una propuesta de síntesis, producto del manejo de la bibliografía especializada y del propio conocimiento de la realidad de las áreas protegidas, sustentada sobre tres pilares esenciales, definidos primeramente para los espacios rurales/naturales en general y posteriormente en su aplicación específica a los espacios sujetos a protección legal (en atención a las singularidades y casuísticas específicas de los mismos).

Entre los criterios propuestos para la turistización de las áreas protegidas (en particular de los Parques) se señalan pues: la necesidad de clarificación tipológica -definiendo con nitidez las posibilidades turísticas existentes así como su imprescindible complementariedad con la oferta de uso público-, la adaptación de dicha turistización a los condicionantes territoriales -concretados en la capacidad de carga-, y el impulso de la coherencia en la intervención mediante la definición de estrategias específicas en materia turística y de uso público y el fomento de la coordinación entre ellas a escala de cada espacio protegido.

Sobre esta base, en las páginas que siguen se plantea un estudio específico respecto de la realidad áreas protegidas-turismo, aplicado al caso del Parque Natural andaluz y, en segunda instancia y su concreción geográfica más particularizada, a los parques naturales declarados en el macizo montañoso de Sierra Morena.

3 Cuya denominación se explicaba por el carácter básico tradicionalmente conferido a la vertiente más estrictamente alojativa de la oferta -e incluso de restauración-, a la que se añadían toda una serie de servicios y actividades -en un sentido eminentemente activo- que contribuyesen a completar o complementar la experiencia de ocio del visitante o turista. 


\section{Cuadro 1 \\ CRITERIOS BÁSICOS PARA EL DESARROLLO TURÍSTICO EN ÁREAS PROTEGIDAS}

\begin{tabular}{|c|c|}
\hline $\begin{array}{c}\text { Criterios generales } \\
\text { para el desarrollo turístico } \\
\text { (espacios rurales/naturales de calidad) }\end{array}$ & $\begin{array}{c}\text { Concreción específica } \\
\text { a las áreas protegidas (AP) }\end{array}$ \\
\hline $\begin{array}{l}\text { - Definición del tipo(s) de turismo a potenciar } \\
\text { en un ámbito dado, en función de sus condi- } \\
\text { cionantes propios y particularizados }\end{array}$ & $\begin{array}{l}\text { - Ir más allá de la mera yuxtaposición entre } \\
\text { modalidades turísticas (turismo de natura- } \\
\text { leza, turismo rural, turismo deportivo,...) } \rightarrow \\
\text { Definir las posibilidades y la oferta básica } \\
\text { para cada tipología } \\
\text { _ Vinculación del turismo con el uso público } \\
\text { (ofertado desde la entidad responsable de la } \\
\text { gestión del AP) } \rightarrow \text { sinergias } \\
\text { - Vinculación con las posibilidades turísticas } \\
\text { en zonas próximas o colindantes al AP } \rightarrow \\
\text { sinergias }\end{array}$ \\
\hline $\begin{array}{l}\text { - Determinación de la capacidad de acogida } \\
\text { turística del ámbito en cuestión, para la pos- } \\
\text { terior adopción de medidas de adaptación de } \\
\text { la afluencia a dicha capacidad predefinida }\end{array}$ & $\begin{array}{l}\text { - Una actividad (turística/uso público) or- } \\
\text { denada sobre el terreno, en función de los } \\
\text { condicionantes territoriales: sobre todo usos } \\
\text { del suelo y propiedad de la tierra y, más en } \\
\text { particular, grado de sensibilidad ambiental } \\
\text { (concretada en la zonificación del AP) } \\
\qquad \downarrow \\
\text { - Limitación al mínimo de la implantación } \\
\text { física (estructuras turísticas/de uso público) y } \\
\text { adaptación de ella a los condicionantes terri- } \\
\text { toriales/ambientales } \\
\text { - Restricción de la afluencia (puntos sensibles) } \\
\rightarrow \text { Factor de incremento de la atracción } \\
\text { turística }\end{array}$ \\
\hline $\begin{array}{l}\text { - Fomento de la coordinación de la totalidad } \\
\text { de las Administraciones concernidas - de una } \\
\text { manera u otra- por el desarrollo turístico del } \\
\text { espacio, con el fin de elaborar un programa } \\
\text { común de actuación }\end{array}$ & $\begin{array}{l}\text { - Necesidad de una estrategia turística propia/ } \\
\text { bien definida para las áreas protegidas (Es- } \\
\text { trategias regionales/autonómicas) } \\
\text { - Necesidad de una estrategia de uso público } \\
\text { para las áreas protegidas (Estrategias regio- } \\
\text { nales/autonómicas) } \\
\qquad \\
\text { - Coordinación entre el ente gestor de las AP } \\
\text { (y de su uso público) y las instancias respon- } \\
\text { sables de la política turística (a la escala de } \\
\text { cada AP) } \\
\qquad \\
\text { - Visión de globalidad de la oferta (turística y } \\
\text { de uso público), para cada AP }\end{array}$ \\
\hline
\end{tabular}

Fuente: elaboración propia. 


\section{EL PARQUE NATURAL ANDALUZ: ENTRE SU VOCACIÓN TURÍSTICA Y LOS DIFÍCILES CONDICIONANTES PARA ELLA}

En relación con lo expuesto, ya en los primeros años 90 se manifestó -desde la Administración autonómica andaluza- que "los Parques Naturales eran lugares idóneos para desencadenar procesos ordenados y sustentables de turismo rural, turismo natural o ecoturismo" (Dirección General de Turismo, 1992, 3), lo que suponía una visión ciertamente avanzada en la línea de la ligazón entre turismo y áreas protegidas ${ }^{4}$.

A un nivel más operativo, ello se situaba en consonancia con la visión amplia y multifuncional del Parque Natural andaluz ${ }^{5}$ en el contexto de la RENPA (Red de Espacios Naturales Protegidos de Andalucía), concretada en la definición de tres grandes objetivos asignados a esta figura protectora: conservación y mejora de los valores y recursos naturales, fomento y ordenación del uso público, e impulso de un desarrollo socioeconómico compatible con la conservación. Parecía claro, pues, que el fomento turístico se hallaba entre los fines perseguidos por el Parque Natural, como uno de los usos o actividades claves para el desarrollo socioeconómico, pero también en la medida en que el uso público - en íntima relación con lo turístico, tal como se ha señalado- se conformaba como objetivo per se de esta figura protectora.

Sin embargo, han sido muy destacadas las insuficiencias registradas en lo relativo a la plasmación efectiva del impulso turístico teóricamente asignado a los parques naturales. Clave para ello ha resultado el modelo de gestión del Parque Natural andaluz, definido en sus líneas básicas en la Ley autonómica 2/1989 y desarrollado e instrumentado desde la pasada década de los noventa hasta la actualidad. Un aspecto esencial de dicho modelo ha radicado en el hecho de que, a diferencia del uso público, la actividad turística no ha contado con una política o estrategia propia y bien definida para su impulso específico -fomento y planificación- en los parques naturales (Pulido, 2005; 2007; Rivera, 2010), lo que se halla a su vez en íntima relación con una dinámica más amplia y de gran calado que ya ha sido considerada en algunas aportaciones anteriores: la difícil instrumentación del objetivo genérico del desarrollo socioeconómico en los parques naturales andaluces (Mulero y Garzón, 2005; Garzón y Ramírez, 2016).

En el marco de dicho panorama global, tan solo cabe reseñar determinados instrumentos administrativos específicamente concebidos para los parques naturales -tales como los Planes de Desarrollo Sostenible (PDS), la Marca Parque Natural de Andalucía o la CETS (Carta de Turismo Sostenible en Espacios Protegidos)-, que han incorporado el turismo entre sus objetivos y acciones propuestas, si bien la recurrente falta de operatividad práctica -a nivel de una efectiva revalorización- de tales instrumentos ha resultado una traba decisiva a este respecto.

4 De hecho, eran varias las afirmaciones recogidas en la obra pionera Ocio y Turismo en los Parques Naturales Andaluces que insistían en la necesaria ligazón entre el turismo rural/natural y los parques naturales. Entre ellas, el que la "Red de Espacios Protegidos es el principal sustento territorial, normativo y de gestión para el desarrollo de un turismo suave en Andalucía" (p. 68), o que "las políticas de desarrollo del turismo rural o turismo verde suponen uno de los pilares estratégicos en las líneas de desarrollo endógeno que desde la Administración se van prefigurando para estos territorios" (p. 74).

5 Gestada durante la pasada década de los 80 y ratificada con la aprobación de la legislación autonómica andaluza en la materia (Ley 2/1989, de 18 de julio, por el que se aprueba de Inventario de Espacios Naturales Protegidos de Andalucía y se establecen medidas adicionales de protección). 
Pese a algunas excepciones en esta dinámica -que serán referidas en el análisis aplicado posterior-, lo cierto es que una proporción mayoritaria de los escasos hitos o logros en materia turística que -en desigual medida- han tenido por escenario los parques naturales cabe situarlos en el marco de la evolución económica global de tales territorios y la política turística desarrollada a escala regional o comarcal por la instancia autonómica competente ${ }^{6}$ y/u otros organismos, con especial relevancia -en este caso- de los Grupos de Desarrollo Rural (GDR), que en no pocos casos han tenido como eje prioritario de su actividad -en sus ámbitos de acción- al sector turístico.

Por su parte, el uso público ha contado, tal como se ha señalado y a diferencia del turismo, con una estrategia propia: Gestión del Uso Público en la RENPA. Estrategia de Acción (Hernández, 2003). Ésta aportaba directrices generales para este campo de acción, si bien con un tratamiento insuficiente de diversos aspectos claves, lo que ha repercutido en la constatación de ciertos desequilibrios y elementos de conflictividad a nivel de su aplicabilidad práctica, en aspectos tales como la planificación de la actividad -mediante los Programas de Uso Público (PUP), inicialmente aprobados para ciertos parques y hoy absolutamente postergados-, o la prácticamente nula ligazón con el campo más específico del turismo.

Tales condicionantes de índole administrativa, ciertamente obstaculizadores en términos generales del desarrollo turístico en los parques naturales andaluces, se han acompañado a su vez de otros condicionantes de índole más estrictamente geográfica. Entre ellos cabe destacar -como factor clave- la acusada disparidad territorial entre parques, lo que ha repercutido en no pocos casos en un potencial turístico muy desigual, como se ha venido manifestando, por ejemplo, entre los seis parques naturales localizados en la Sierra Morena andaluza, cuya casuística específica -o al menos las grandes claves de la misma- pasamos a considerar, bajo la convicción de su alta representatividad de todo lo expuesto hasta este punto del trabajo.

\section{SIERRA MORENA: LA CONSTATACIÓN DE LA COMPLEJIDAD Y LA DIS- PARIDAD}

Sierra Morena se configura como una montaña media mediterránea, marcada por el predominio de los usos agrarios tradicionales y de carácter extensivo (sobre todo ganaderos y cinegéticos), lo que explica su notable cualificación ambiental y -en determinados sectores- excepcional valor ecológico (Valle, 2001).

Sobre la base de esta configuración, no son pocos los rasgos limitadores del desarrollo turístico comunes al conjunto del macizo montañoso, derivados de factores tales como su elevada impenetrabilidad (en función sobre todo de su complejidad orográfica y una propiedad privada mayoritaria), los condicionantes climáticos -particularmente el calor estival-, el menor grado de espectacularidad paisajística respecto de otros ámbitos (principalmente de alta montaña), o el escaso grado general de antropización y urbanización directa, lo que explica la ausencia de una vertiente artística o monumental tan relevante como en otras zonas rurales.

Pese a ello, el diseño territorial de los seis parques mariánicos (Figura 1) evidencia, en la línea de lo apuntado con anterioridad, importantes disparidades en aspectos claves

6 Que, tras varios cambios, ostenta en la actualidad la denominación de Consejería de Turismo y Deporte. 
para su potencial turístico, tales como su extensión, número de municipios implicados, intensidad de la antropización y transformación de la base natural originaria, e incidencia de todo ello en la configuración geográfica y paisajística. Cabe diferenciar de esta forma dos modelos básicos de parques naturales: los grandes parques del sector occidental del macizo (Sierra de Aracena y Picos de Aroche, y Sierra Norte de Sevilla), de escala comarcal y marcados por su notable humanización y diversidad interna; y los parques de Sierra Morena centro-oriental (parques cordobeses -Sierra de Hornachuelos y Sierra de Cardeña y Montoro- y jiennenses -Sierra de Andújar y Despeñaperros), de menor extensión y mayor homogeneidad y relevancia ambiental y ecológica.

\section{Figura 1 \\ LOCALIZACIÓN DE LOS PARQUES NATURALES DE LA SIERRA MORENA ANDALUZA}

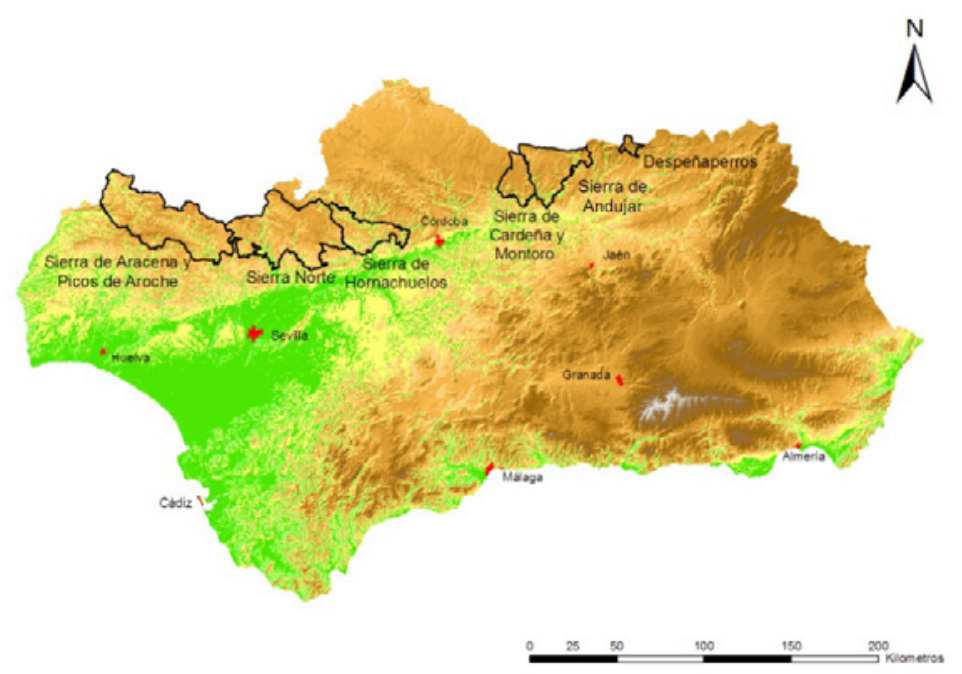

Fuente: Modelo Digital de Elevaciones de Andalucía (20 metros) y Mapa Digital de Andalucía. Elaboración propia.

Así pues, lo señalado, junto a los condicionantes de índole administrativa referidos en el apartado anterior, explican que la funcionalidad turística en los parques naturales de la Sierra Morena andaluza haya alcanzado un desarrollo pobre, aunque dispar.

Las iniciativas públicas para el fomento turístico con incidencia en los territorios protegidos han resultado escasas y fundamentalmente provenientes del campo del uso público. Muy pocas han sido las iniciativas específicamente turísticas y en su mayor parte sin una vinculación explícita con la realidad Parque Natural, al coincidir bien con determinados instrumentos de planificación turística bien con acciones directamente impulsadas desde los GDR en sus ámbitos comarcales de acción.

A escala del macizo mariánico -desde una visión de globalidad- las iniciativas turísticas se han limitado a una primordial, si bien de especial interés. Ésta se deriva de la creación de la Asociación para el Desarrollo Integral del Territorio (ADIT) de Sierra 
Morena, entidad de carácter aglutinador de aquellos organismos -esencialmente públicos- implicados en el desarrollo turístico en los cuatro ámbitos comarcales concernidos (Sierra de Aracena y Picos de Aroche, Sierra Morena Sevillana, Sierra Morena Cordobesa, y Campiña Norte de Jaén) ${ }^{7}$, y constituida con el objetivo primordial de la elaboración y desarrollo del Plan Turístico de Sierra Morena (ADIT Sierra Morena, 2006). Pese a lo ambicioso de la iniciativa, lo cierto es que las intervenciones in situ no han mostrado una gran intensidad, en lo que sin duda ha repercutido la gran extensión del territorio concernido. En este sentido, al margen de las ayudas para la creación o mejora de diversos establecimientos turísticos (alojamiento y restauración), las acciones de mayor calado han sido tres: la recuperación e integración de caminos públicos para la puesta en servicio del sendero GR-48 Sierra Morena; la implantación de una señalización homogénea en el conjunto del ámbito del Plan -señalización de diverso carácter: direccional, descriptiva de localidades (Figura 2), y explicativa de hitos constructivos específicos, principalmente-, lo que sin embargo no se ha acompañado en la mayor parte de los casos de una acción específica de revalorización patrimonial y turística; y, en tercer lugar, el impulso a la certificación de Sierra Morena como Reserva y Destino Turístico Starlight, avalada por la UNESCO y la Organización Mundial del Turismo (OMT) y que reconoce la calidad del espacio mariánico andaluz para el turismo astronómico, cuyo proceso de funcionalización efectiva -en forma de productos turísticos- se halla en desarrollo en la actualidad ${ }^{8}$.

\section{Figura 2}

\section{PANEL EXPLICATIVO DE LA LOCALIDAD DE FUENTEHERIDOS (PARQUE NATURAL SIERRA DE ARACENA Y PICOS DE AROCHE), EN EL MARCO DEL PLAN TURÍSTICO SIERRA MORENA}

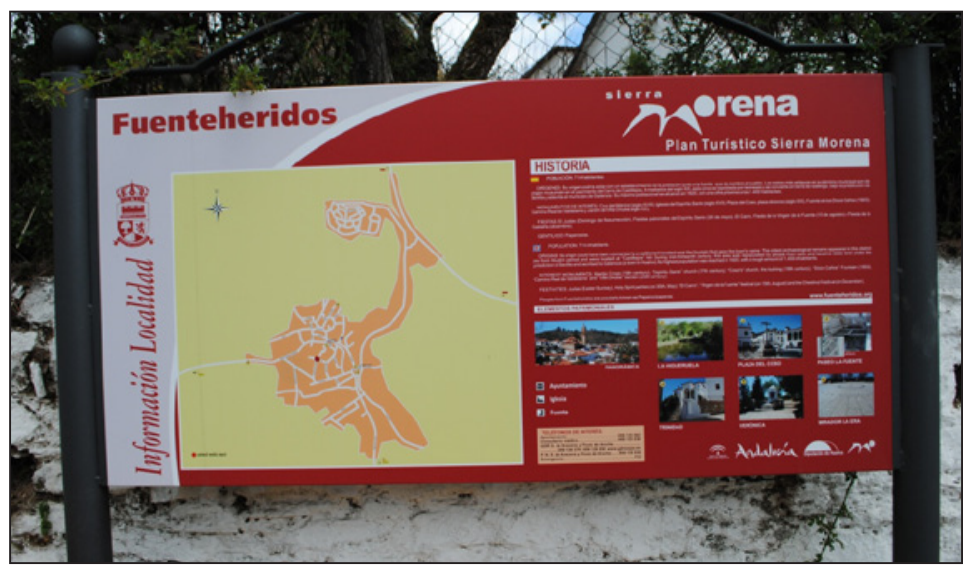

Fuente: elaboración propia.

7 Los miembros de la ADIT Sierra Morena son: los cuatro GDR actuantes cada una de las comarcas referidas, los 57 ayuntamientos de dicho territorio, las Mancomunidades de Municipios, las Diputaciones Provinciales de las provincias de Jaén, Córdoba, Sevilla y Huelva, así como entidades empresariales del sector turístico que ejercen su actividad en Sierra Morena (www.sierramorena.com).

8 Puede consultarse al respecto la web http://www.astronomiasierramorena.org 
Figura 3

\section{SENDERO GR-48 SIERRA MORENA}

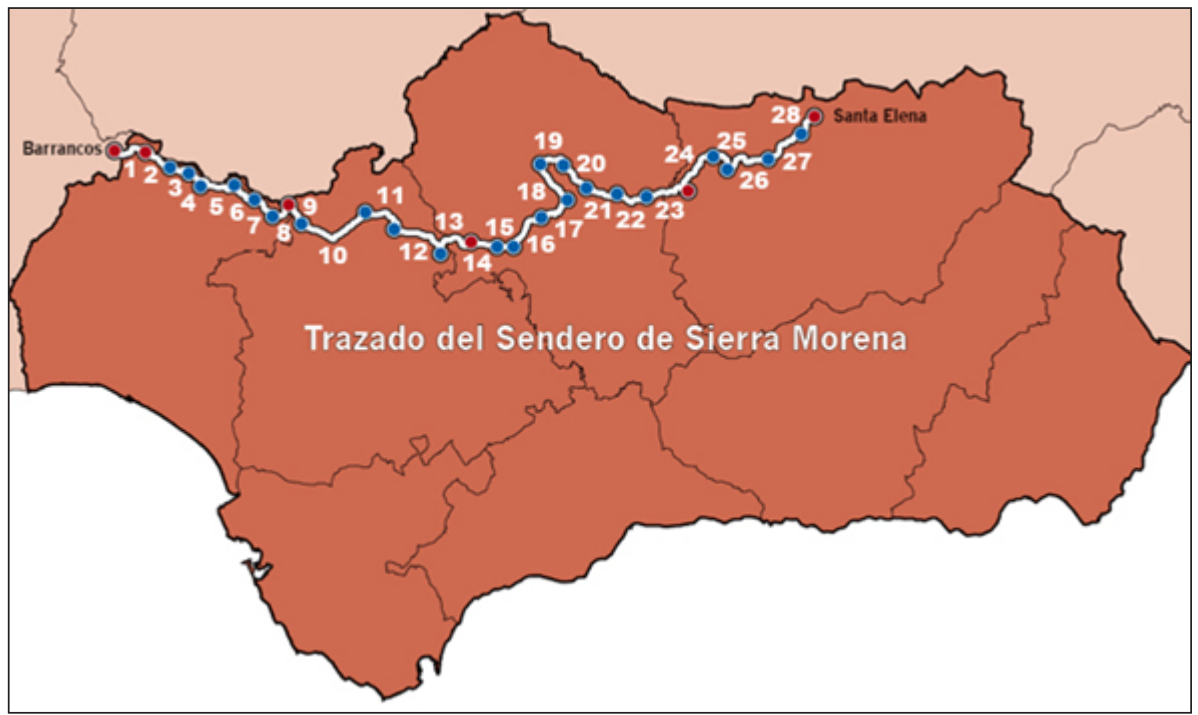

Fuente: http://senderogr48.sierramorena.com/itinerario

No obstante, iniciativas como esta $-\mathrm{u}$ otras en materia turística- se han hallado al margen de una efectiva coordinación con los Parques Naturales. Prueba de ello es, por ejemplo, el diseño del sendero GR-48, que muestra una incidencia muy desigual sobre el territorio de los parques (Figura 3).

Además, tal como se apuntó líneas atrás, las iniciativas turísticas específicamente vinculadas a la realidad Parque Natural han resultado, al margen del uso público, muy puntuales, lo que se explica en buena medida por la ya referida inoperatividad de los instrumentos administrativos de fomento del desarrollo en los parques andaluces. Ello se ha hecho particularmente patente en el caso de los PDS -a tenor de las carencias de su modelo de gestión, que imposibilitaba en gran medida la ejecución del elevado número de acciones-medidas propuestas (Mulero y Garzón, 2005)-, pero también de la CETS y la Marca Parque Natural, concebidos como sellos de calidad pero de escasa o nula aplicabilidad práctica. Los datos reflejados en el Cuadro 2 -relativos a la aplicación de la Marca Parque a iniciativas empresariales del sector del turismo de naturaleza en municipios de los parques- así lo ratifican, al mostrar un evidente estancamiento, e incluso retroceso, reciente de las empresas adheridas, a escala andaluza y aún de manera más acusada en los parques de Sierra Morena

En todo caso, tales dinámicas generales se acompañan, como se ha anticipado, de notables disparidades entre parques, en función de la especificidad de sus condicionantes así como de ciertas casuísticas registradas. A la consideración más detallada de tales disparidades, de singular interés al evidenciar diversas posibilidades y limitaciones particulares para el desarrollo turístico en áreas protegidas, se dedican las páginas que siguen. 


\section{Cuadro 2}

\section{VISIÓN COMPARATIVA DE LA APLICACIÓN DE LA MARCA PARQUE NATURAL EN ANDALUCÍA Y SIERRA MORENA}

\begin{tabular}{|c|c|c|c|c|c|c|c|c|c|c|c|c|c|c|}
\hline & \multicolumn{10}{|c|}{ Empresas adheridas al sector del turismo de naturaleza } \\
\hline Año & 2001 & 2002 & 2003 & 2004 & 2005 & 2006 & 2007 & 2008 & 2009 & 2010 & 2011 & 2012 & 2013 & 2014 \\
\hline Andalucía & 6 & 8 & 24 & 39 & 67 & 89 & 100 & 106 & 106 & 98 & 93 & 103 & $\mathrm{Sd}$ & 99 \\
\hline Sa Morena & 3 & 3 & 3 & 8 & 10 & 18 & 19 & 22 & 22 & 24 & 16 & 17 & $\mathrm{Sd}$ & 14 \\
\hline
\end{tabular}

Fuente: Consejería de Medio Ambiente (varios años). Elaboración propia.

\subsection{Grandes parques occidentales: una tendencia expansiva aunque carente de la necesaria articulación e integración}

Los Parques Naturales Sierra de Aracena y Picos de Aroche y Sierra Norte de Sevilla presentan en términos generales condicionantes territoriales algo más favorables para su desarrollo turístico, particularmente su extensión (por encima en ambos casos de las 150.000 hectáreas) y proyección comarcal, lo que explica otros aspectos tales como la inclusión de numerosos núcleos de población dentro de los límites protegidos, o su significativa diversidad patrimonial y paisajística (especialmente relevante en el contexto de Sierra Morena). Aún con todo, la oferta turística resultaba c inexistente en el momento de la declaración de ambos parques (1989), salvo excepciones puntuales -caso de la temprana funcionalización de la Gruta de las Maravillas en Aracena- pese a lo cual sí se registraba un uso recreativo de notable intensidad en determinados enclaves de especial atractivo (Dirección General de Turismo, 1992).

Sobre esta modesta base, ya desde los primeros años de la evolución de los parques (década de los noventa) se registró en sendos ámbitos territoriales un auténtico despertar turístico, lo que denota con nitidez -como dinámica clave- una indudable influencia de la protección sobre la proyección turística de los territorios concernidos. Cabe cuestionarse en todo caso acerca de los condicionantes de dicha influencia.

En este sentido, la temprana implicación de la iniciativa privada se vio respaldada primeramente por diversas medidas específicas de impulso a proyectos de emprendimiento en los parques naturales. No obstante, éstas se limitaron en lo esencial -al menos en un principio- a las ayudas del IFA ${ }^{9}$, que en todo caso gozaron de mayor impacto en la Sierra de Aracena y Picos de Aroche, al tratarse del único de los seis parques mariánicos que contó con una Gerencia de Promoción, instrumento concebido por la Ley autonómica 2/1989 para el impulso e instrumentación de las acciones del IFA en los parques naturales (Garzón y Ramírez, 2016).

Tales ayudas mostraron sin embargo una incidencia decreciente en el tiempo, frente al papel creciente asumido por aquellas provenientes de iniciativas comunitarias, canalizadas a través de los GDR. En este sentido, la escala comarcal de que se dotó a sendos parques naturales se ha constituido como un factor decisivo para el desarrollo turístico (y socioeconómico, en términos más globales), por cuanto el ámbito de acción de los GDR se ha identificado en lo esencial con los territorios protegidos y sus AISE ${ }^{10}$ (Figura 4). Dicha

9 Instituto de Fomento de Andalucía. Desde 2005 Agencia IDEA (Innovación y Desarrollo de Andalucía).

10 Áreas de Influencia Socioeconómica, coincidentes con la totalidad de los términos de aquellos municipios que aportan territorio al parque natural (en cuestión). 
coincidencia territorial repercutió -como hecho clave- en la paulatina interacción entre sendas realidades (Parque Natural y desarrollo rural), lo que ha tenido efectos ciertamente positivos en términos de impulso turístico, particularmente en el caso de la Sierra de Aracena y Picos de Aroche, donde dicha interacción ha resultado más estrecha y evidente (Romero et al., 2011).

\section{Figura 4}

\section{ÁMBITOS DE ACCIÓN DE LOS GDR SIERRA DE ARACENA Y PICOS DE AROCHE Y SIERRA MORENA SEVILLANA, PRÁCTICAMENTE COINCIDENTES CON LAS AISE}
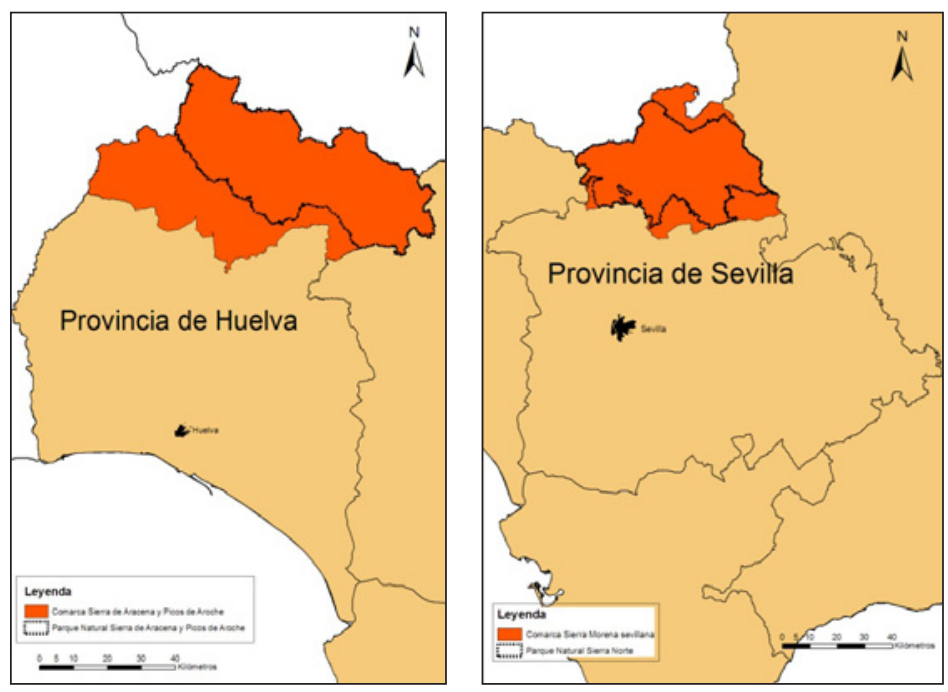

Fuente: elaboración propia.

En efecto, las ayudas enmarcadas dentro de las iniciativas LEADER (sobre todo II y Plus) y FEADER se han perfilado como el vector primordial para el impulso turístico en los territorios concernidos por sendos parques naturales, como lo muestran los datos específicos de que hemos podido disponer para la Sierra de Aracena y Picos de Aroche (Cuadro 3).

Pero más allá de la frialdad de las cifras, un análisis más detallado y de índole cualitativa (sustentado en un exhaustivo trabajo de campo) nos permite discernir la realidad del desarrollo turístico en sendos espacios protegidos y la incidencia de la variable Parque Natural. En este sentido, en el marco de un impulso primordial a la conformación de un significativo entramado alojativo turístico (Cuadro 3), debe destacarse la opción preferencial -desde los GDR- por el fomento de establecimientos de calidad, mediante el acondicionamiento de estructuras edificatorias previas, en su mayoría localizadas en el medio agrario y forestal, conformando productos singulares que además en no pocos casos -sobre todo desde la primera década del siglo XXI- comenzaron a incorporar servicios de turismo activo y/o interpretativo (Figura 5). 


\section{Cuadro 3}

AYUDAS VINCULADAS AL DESARROLLO TURÍSTICO FINANCIADAS MEDIANTE LAS INICIATIVAS LEADER II Y LEADER + EN LA SIERRA DE ARACENA Y PICOS DE AROCHE

\begin{tabular}{|c|c|c|c|}
\hline \multicolumn{2}{|c|}{ LEADER II } & \multicolumn{2}{c|}{ LEADER Plus } \\
\hline Concepto & Subvención $(\boldsymbol{€})$ & Concepto & Subvención (€) \\
\hline Turismo rural & $1.391 .343,02$ & Alojamientos turísticos & $1.589 .445,28$ \\
\hline $\begin{array}{c}\text { Conservación y mejora del } \\
\text { patrimonio }\end{array}$ & $190.520,83$ & Hostelería & $58.475,02$ \\
\hline- & - & Empresas de turismo activo & $76.244,99$ \\
\hline- & - & Infraestructuras turísticas & $438.478,02$ \\
\hline- & - & Rehabilitación del patrimonio & $249.546,68$ \\
\hline
\end{tabular}

Fuente: Grupo de Desarrollo Rural Sierra de Aracena y Picos de Aroche. Elaboración propia.

Figura 5

ESTABLECIMIENTOS TURÍSTICOS DE CALIDAD

CERTIFICADOS CON LA MARCA PARQUE NATURAL EN LA SIERRA DE ARACENA Y PICOS DE AROCHE

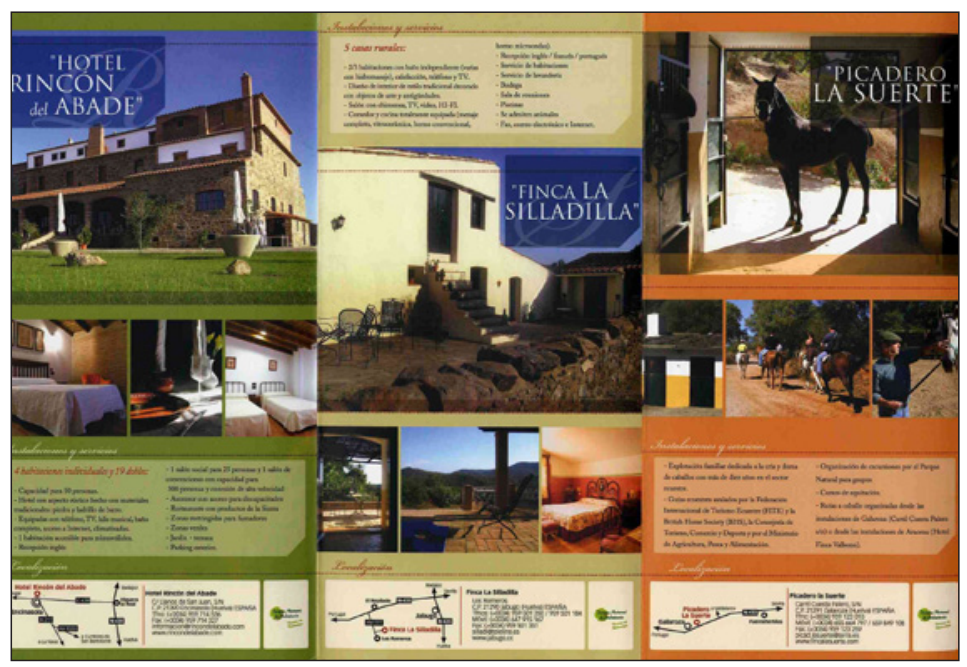

Fuente: Grupo de Desarrollo Rural Sierra de Aracena y Picos de Aroche, y cortesía de la Casa Rural Las Navezuelas (Cazalla de la Sierra).

Pero, junto al propio impulso dotacional, desde ambos GDR (Sierra de Aracena y Picos de Aroche y Sierra Morena Sevillana) se vino planteando -ya desde los primeros años del siglo XXI- una praxis que estimamos ciertamente interesante, en un sentido dinamizador, si bien más allá de la estricta financiación; nos referimos al fomento del empleo de nuevos mecanismos derivados de la realidad Parque Natural para la cualificación y difusión de la oferta turística. Tal es el caso de las certificaciones de calidad, como la CETS y, sobre 
todo, la Marca Parque Natural de Andalucía. Incluso, en el caso más singular del GDR onubense se ha pretendido ir más allá, planteando una intervención de alcance más global, en el sentido de definir una oferta de establecimientos y servicios turísticos de calidad bien reconocible para el conjunto de la Sierra de Aracena y Picos de Aroche (Figura 5). No obstante, la precariedad -apuntada más arriba- en el empleo de la Marca Parque Natural a escala andaluza y de Sierra Morena, a tenor de su escasa virtualidad para una efectiva revalorización y difusión de los productos de los espacios protegidos, ha repercutido en la reciente paralización de iniciativas de promoción conjunta como la referida.

Además de ello, otro aspecto clave para la adecuada comprensión de la dinámica turística de los parques naturales onubense y sevillano radica en la estructuración territorial de su oferta de establecimientos y servicios. Se ha venido constatando en ambos casos un notable desequilibrio a tenor de la fuerte concentración en una serie reducida de municipios centrales de los espacios protegidos, como de hecho se muestra en la Figura 6, relativa a los establecimientos turísticos rurales ${ }^{11}$, mayoritarios en sendos parques naturales. Cuestionándonos acerca del por qué de dicha dinámica, al margen de aspectos más o menos básicos (como por ejemplo la entidad poblacional de algunos de esos municipios centrales, o el mayor atractivo de ciertos enclaves...), estimamos que el factor primordial ha radicado en las posibilidades turísticas sobre el terreno, es decir, en la oferta de actividades de conocimiento, disfrute e interpretación de los recursos del patrimonio natural -pero también cultural- de los espacios protegidos, muy localizada en tales sectores centrales.

Un papel clave a este respecto (al tratarse, tal como se apuntó, de la principal aportación de la realidad Parque Natural al desarrollo turístico) ha correspondido a la oferta de uso público. El uso público ha venido contando, ya desde fechas tempranas (década de los noventa) con una dotación numerosa en equipamientos y servicios en ambos espacios, si bien marcada asimismo por su escasa diversificación tipológica (al limitarse en lo esencial a senderos señalizados, miradores y áreas recreativas) y una gran polarización en las áreas centrales de los territorios protegidos, en torno a los ejes conformados por la Sierra de Aracena -en el caso onubense- y Cerro del Hierro-Rivera del Huéznar -en el caso sevillano- (Figura 7). Ha resultado evidente (aún hasta la actualidad) la debilidad del uso público en los sectores periféricos, con equipamientos escasos y marcados por una acusada dispersión y desarticulación territorial, lo que ha repercutido -en suma- en el pobre desarrollo de la oferta más específicamente turística.

En este sentido, ya desde la primera década del siglo XXI se plantearon, desde los PUP de los parques naturales (aprobados respectivamente en 2003 y 2004) diversas iniciativas, que han tratado de responder -con éxito dispar- a tales casuísticas. A este respecto, frente al escaso impacto de la intervención emprendida en el parque onubense -con intervenciones puntuales que no resolvían el problema de la infradotación y la dispersión de la oferta de uso público en los sectores periféricos-, sí resultaron especialmente significativas dos iniciativas planteadas en la Sierra Norte de Sevilla (Garzón y Arias, 2008). Nos referimos a la conformación de un segundo núcleo de uso público en el extremo occidental del parque (aprovechando la existencia de varias fincas públicas en ese sector), así como el acondicionamiento de la Vía Verde de la Sierra Norte, dotación de extraordinaria relevancia a

11 Incluyendo tanto casas rurales como viviendas turísticas de alojamiento rural. 
tenor de su gran atractivo y su carácter integrador de diversos recursos y dotaciones de en este entorno (Figuras 7 y 8). El aprovechamiento de los hitos de dominio público -en particular las fincas públicas ${ }^{12}$ - en el caso del parque sevillano no ha sido tal en el caso de su homólogo onubense.

\section{Figura 6 \\ DISTRIBUCIÓN TERRITORIAL DE LOS ESTABLECIMIENTOS TURÍSTICOS RURALES EN MUNICIPIOS DE LOS PARQUES NATURALES SIERRA DE ARACENA Y PICOS DE AROCHE Y SIERRA NORTE (AÑO 2010)}

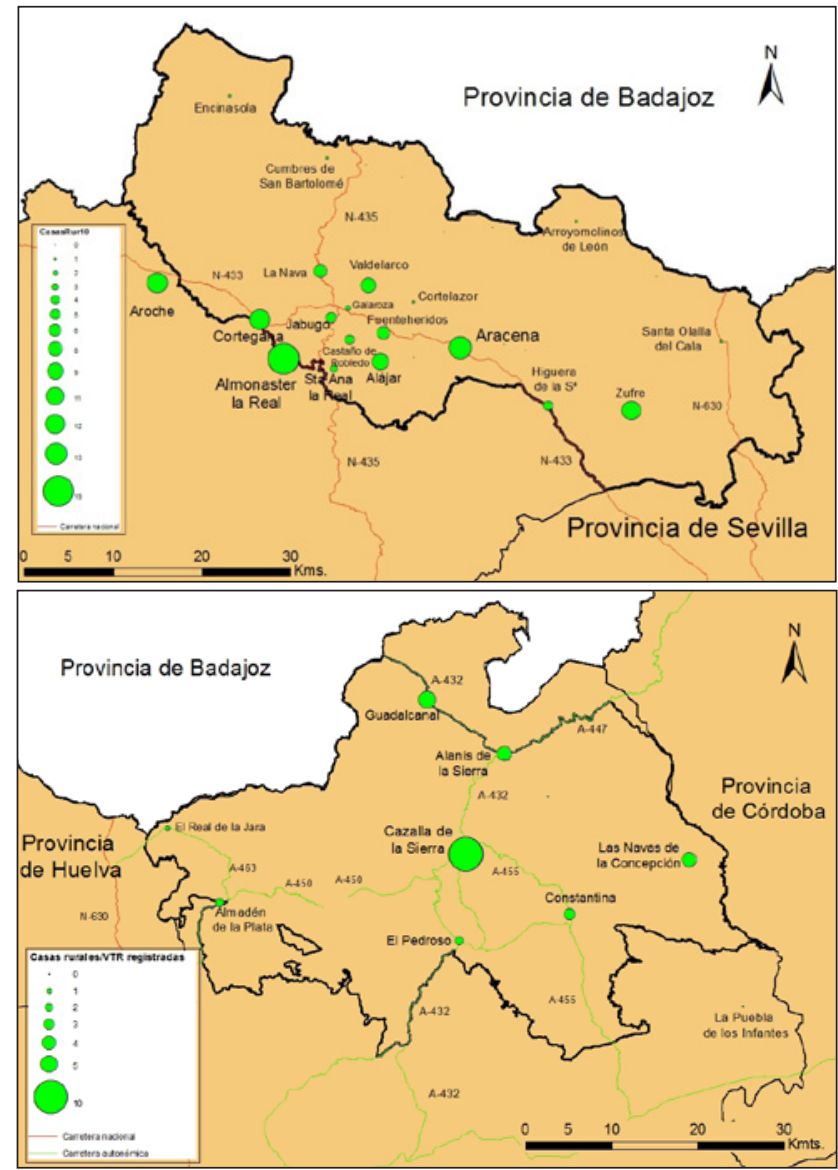

Fuente: Sistema de Información Multiterritorial de Andalucía (SIMA) y Datos Espaciales de Andalucía para Escalas Intermedias (DEA-100). Elaboración propia.

12 La información - documental y cartográfica- referida a los montes públicos andaluces se encuentra disponible (en la web www.juntadeandalucia.es/medioambiente) desde el año 2012 a raíz de la promulgación de la Orden de 23 de febrero de 2012 por la que se da publicidad a la relación de montes incluidos en el Catálogo de Montes de Andalucía. 
Figura 7

EQUIPAMIENTOS DE USO PÚBLICO DE LOS PARQUES NATURALES SIERRA DE ARACENA Y PICOS DE AROCHE Y SIERRA NORTE DE SEVILLA SEGÚN SUS PUP
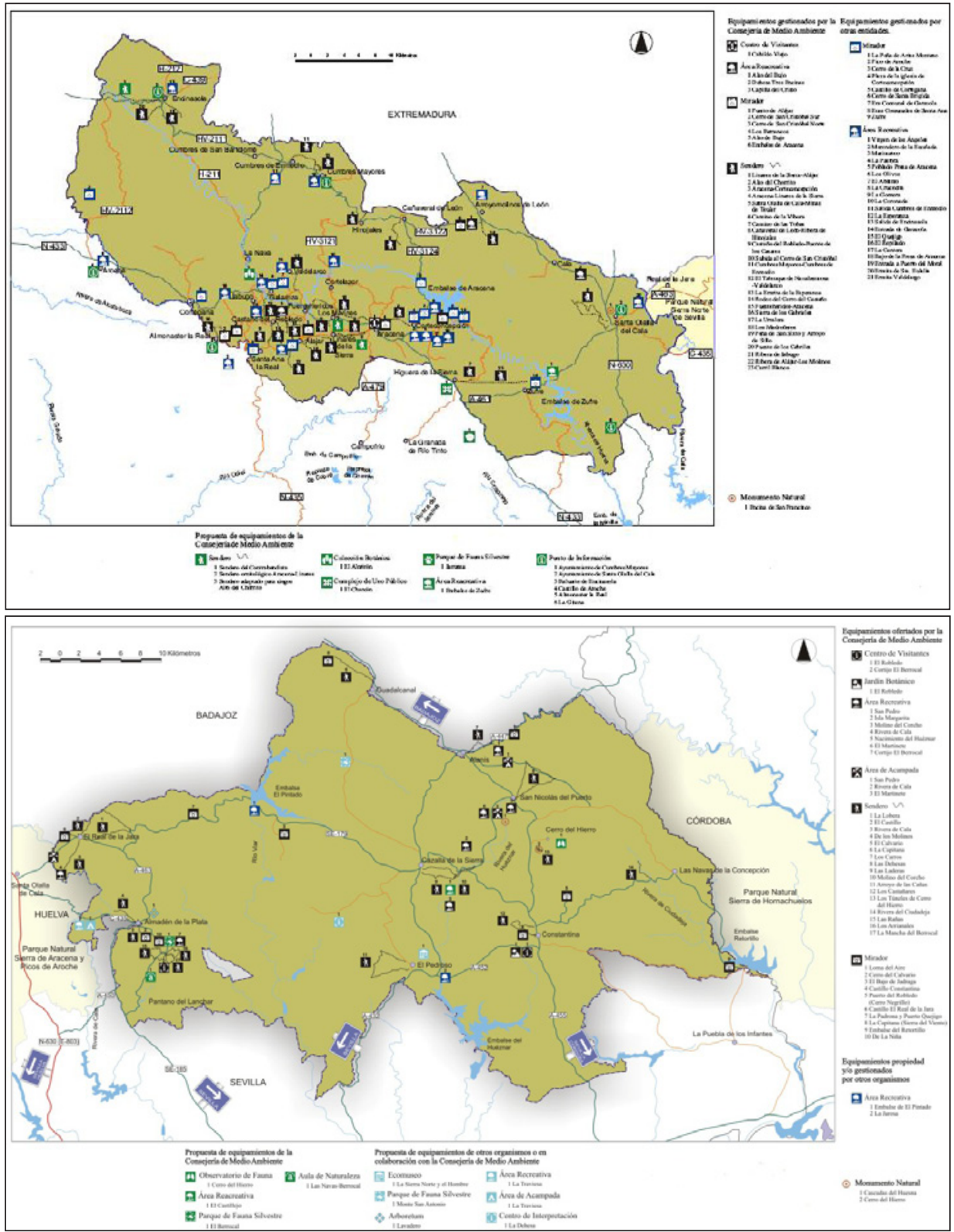

Fuente: Consejería de Medio Ambiente (www.juntadeandalucia.es/medioambiente). 
En todo caso, y al margen de los logros reseñados, siguen siendo patentes ciertas carencias de fondo para un desarrollo turístico verdaderamente significativo, globalizador y adaptado a la especificidad de los territorios protegidos. Entre ellos destaca sobremanera la falta de una más ambiciosa diversificación territorial de la oferta de uso público, ya que resulta aún en buena medida desarticulada y desequilibrada, tanto en la dotación como en la afluencia registrada, incluso con ciertos problemas de congestión de usuarios, particularmente en ciertos enclaves del eje de la Rivera del Huéznar (Sierra Norte). Pero también se plantean otros desafíos, como es el caso -muy singularmente- de la escasa revalorización de recursos culturales (Romero et al., 2011), pese a algunas iniciativas pioneras -de iniciativa autonómica o municipal-en ambos parques naturales, principalmente en la Sierra de Aracena y Picos de Aroche (Figura 8).

\section{Figura 8 \\ RECORRIDO DE LA VÍA VERDE DE LA SIERRA NORTE Y FUNCIONALIZACIÓN TURÍSTICA DEL YACIMIENTO ARQUEOLÓGICO DE TUROBRIGA (AROCHE)}
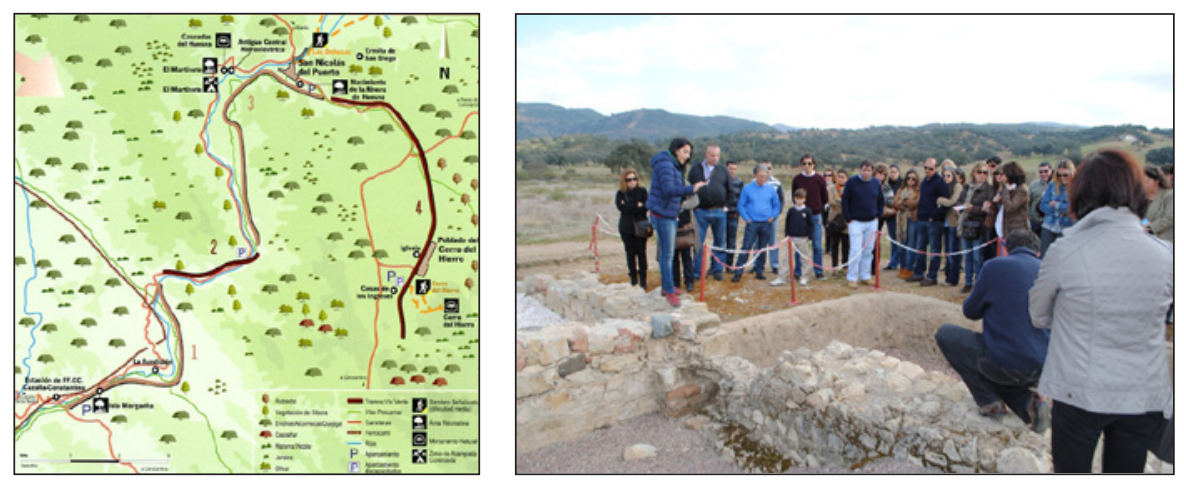

Fuente: Cortesía de la Dirección del Parque Natural Sierra Norte, y elaboración propia.

En general, no se ha operado hasta la fecha una verdadera integración entre los vectores claves que constituyen la revalorización patrimonial, el uso público y el turismo. De hecho, pese al notable desarrollo alojativo y su importante grado de ocupación turística y a las importantes afluencias puntuales a hitos singulares (del patrimonio natural y, en menor medida, cultural), los equipamientos de acogida e información de sendos parques naturales han venido registrando en general datos modestos de usuarios ${ }^{13}$, hecho ciertamente representativo que denota con claridad la falta de integración antes apuntada en la dinámica turística global de las áreas protegidas.

La no aprobación de nuevos PUP -tras la culminación de su periodo de vigencia de cuatro años- ha contribuido a ello. La ordenación global de la actividad turística parece

13 Como se constata en los datos aportados desde los Centros de Visitantes de sendos parques naturales, que han registrado de manera bastante continuada afluencias en el entorno de los 10.000 usuarios anuales. Tales datos aparecen recogidos en los Informes de Medio Ambiente en Andalucía, en la sección Estadísticas (https:// www.juntadeandalucia.es/medioambiente/site/ima). 
haberse encomendado a las CETS, sello de calidad turística con la que fueron acreditados sendos espacios: Sierra de Aracena y Picos de Aroche en 2004 (siendo renovada la certificación en 2010) y la Sierra Norte en 2007 (con renovación en 2012).

Las CETS ${ }^{14}$ fueron impulsadas desde los Parques Naturales, si bien con un importante papel de otros agentes -principalmente los GDR-en su difusión y dinamización en aras de su aplicación. La implantación de las CETS se instrumentó mediante la elaboración de una Estrategia para cada parque natural, que se desarrollaría mediante un Plan de Acción de aplicación durante cada periodo de acreditación. Lo más relevante a nuestro juicio radica en el modelo turístico integrador - de los territorios protegidos y su oferta patrimonial y turística- por el que parece apostar la CETS, a tenor de las líneas estratégicas y actuaciones que se han venido definiendo (Cuadro 4).

Pero, junto a ello, debe destacarse como un aspecto clave la recurrente falta de operatividad de la Carta, que por su propio carácter de certificación ha venido careciendo hasta la fecha de mecanismos para garantizar su plena efectividad (desarrollo de actuaciones específicas), más allá del compromiso -en gran medida voluntarista y, por ello, ciertamente desigual- asumido por los agentes concernidos por ella. La intervención efectiva ha resultado, pues, limitada, centrada en lo esencial en el impulso de la Fase II de la CETS: la adhesión de establecimientos y servicios turísticos a la Carta y su conformación como integrantes de una red de Puntos de Información de los parques naturales; en 2015 eran ya 16 las empresas adheridas en la Sierra de Aracena y Picos de Aroche, y siete en la Sierra Norte ${ }^{15}$. No se han abordado, por el contrario, los retos de fondo aún patentes en materia turística en los dos grandes parques naturales de Sierra Morena occidental, a nivel de reforzamiento e integración territorial de las posibilidades turísticas sobre el terreno.

\section{Cuadro 4 \\ GRANDES DIRECTRICES Y ACTUACIONES COMUNES EN LAS ESTRATEGIAS DE LA CETS DE LOS PARQUES NATURALES SIERRA DE ARACENA Y PICOS DE AROCHE Y SIERRA NORTE}

\begin{tabular}{|l|l|c|}
\hline \multicolumn{1}{|c|}{$\begin{array}{c}\text { Grandes } \\
\text { Directrices }\end{array}$} & \multicolumn{1}{|c|}{ Actuaciones } & Entidad responsable \\
\hline $\begin{array}{l}\text { 1. Mejora de la } \\
\text { calidad de la oferta } \\
\text { turística }\end{array}$ & $\begin{array}{l}\text { 1.1. Creación de un foro de participación entre diferentes } \\
\text { actores del sector turístico }\end{array}$ & $\begin{array}{c}\text { Parque Natural y } \\
\text { GDR }\end{array}$ \\
\cline { 2 - 3 } & $\begin{array}{l}\text { 1.2. Alcanzar la certificación del sistema de calidad turística de } \\
\text { los servicios de uso público en el parque natural }\end{array}$ & Parque Natural \\
\cline { 2 - 3 } & $\begin{array}{l}\text { 1.3. Impulso a la continuidad de la Marca Parque Natural e } \\
\text { implantación del Sistema de Calidad Turístico Español (SCTE) }\end{array}$ & GDR \\
\cline { 2 - 3 } & $\begin{array}{l}\text { 1.4.Implantación del sistema de acreditación de establecimientos } \\
\text { turísticos como puntos de información del parque natural }\end{array}$ & GDR \\
\hline
\end{tabular}

14 Los fundamentos (objetivos y metodología) de esta herramienta se recogen en la web http://www.redeuroparc.org/actividades/carta-europea-turismo-sostenible

15 Igualmente tales datos se hallan recopilados en la sección de Estadísticas de los Informes de Medio Ambiente en Andalucía (https://www.juntadeandalucia.es/medioambiente/site/ima). 


\begin{tabular}{|c|c|c|}
\hline \multirow{2}{*}{$\begin{array}{l}\text { 2. Control de la } \\
\text { frecuentación } \\
\text { turística }\end{array}$} & $\begin{array}{l}\text { 2.1. Estudio de cuantificación y caracterización de visitantes del } \\
\text { parque natural }\end{array}$ & Parque Natural \\
\hline & 2.2. Estudio de capacidad de acogida & Parque Natural \\
\hline \multirow{6}{*}{$\begin{array}{l}\text { 3. Creación de } \\
\text { una oferta turística } \\
\text { específica del } \\
\text { Espacio Natural } \\
\text { Protegido y } \\
\text { marketing } \\
\text { responsable }\end{array}$} & 3.1. Plan de mejora de los equipamientos de uso público & Parque Natural \\
\hline & 3.2. Mejora de señalización turística del AISE & GDR \\
\hline & 3.3. Plan de diversificación de la oferta turística & $\begin{array}{l}\text { Parque Natural, GDR, } \\
\text { empresarios }\end{array}$ \\
\hline & $\begin{array}{l}\text { 3.4. Elaboración de un programa de información del parque } \\
\text { natural }\end{array}$ & Parque Natural \\
\hline & $\begin{array}{l}\text { 3.5. Realización de un estudio de mercado de la oferta específica } \\
\text { ligada al parque natural }\end{array}$ & GDR \\
\hline & 3.6. Plan de marketing del destino Parque Natural & $\begin{array}{l}\text { GDR, Parque Natural, } \\
\text { empresarios }\end{array}$ \\
\hline \multirow[t]{2}{*}{$\begin{array}{l}\text { 4. Comunicar, } \\
\text { educar y formar }\end{array}$} & $\begin{array}{l}\text { 4.1. Programa de divulgación y educación ambiental del parque } \\
\text { natural }\end{array}$ & Parque Natural \\
\hline & $\begin{array}{l}\text { 4.2. Programa de formación para profesionales del sector } \\
\text { turístico }\end{array}$ & GDR \\
\hline $\begin{array}{l}\text { 5. Conservación y } \\
\text { puesta en valor del } \\
\text { patrimonio }\end{array}$ & 5.1. Valorización del patrimonio cultural en el AISE & GDR \\
\hline \multirow{2}{*}{$\begin{array}{l}\text { 6. Apoyo a la } \\
\text { economía local y } \\
\text { calidad de vid }\end{array}$} & $\begin{array}{l}\text { 6.1. Apoyo a iniciativas de transformación de productos locales } \\
\text { para su mejor comercialización entre los turistas }\end{array}$ & GDR \\
\hline & $\begin{array}{l}\text { 6.2. Implantación de Agendas } 21 \text { y sistemas de gestión } \\
\text { medioambiental }\end{array}$ & GDR y ayuntamientos \\
\hline
\end{tabular}

Fuente: Estrategias de la CETS de los Parque Naturales Sierra de Aracena y Picos de Aroche y Sierra Nortea (documentación obtenida por cortesía de los GDR Sierra de Aracena y Picos de Aroche y Sierra Morena Sevillana). Elaboración propia.

\subsection{La debilidad turística de los parques de Sierra Morena centro-oriental}

A diferencia de los dos parques naturales del sector occidental del macizo mariánico andaluz, los parques cordobeses y jiennenses han sustentado desde su declaración un desarrollo turístico que, pese a ciertas aportaciones de indudable interés, ha resultado modesto en términos generales (Dirección General de Turismo, 1992; Luque, 2003; Araque et al., 2005). Entre los factores explicativos de dicha realidad se hallan nuevamente condicionantes territoriales y, en relación con ellos, otros relativos a la propia gestión administrativa desarrollada.

Quizá el factor geográfico más destacado radica en el diseño y delimitación territorial de estos parques naturales y la escala empleada para ello. A este respecto, debe destacarse como se ha otorgado protección a sectores territoriales más específicos, carentes de la proyección comarcal de los grandes parques occidentales (Figura 9). 


\section{Figura 9 \\ ÁMBITOS DE ACCIÓN DE LOS GDR DE LA SIERRA MORENA CORDOBESA Y JIENNENSE EN RELACIÓN CON LOS PARQUES NATURALES}

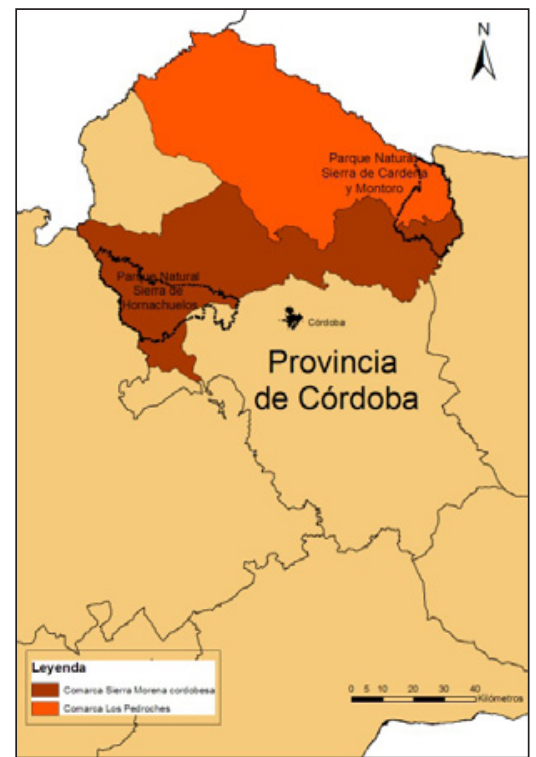

Fuente: elaboración propia.

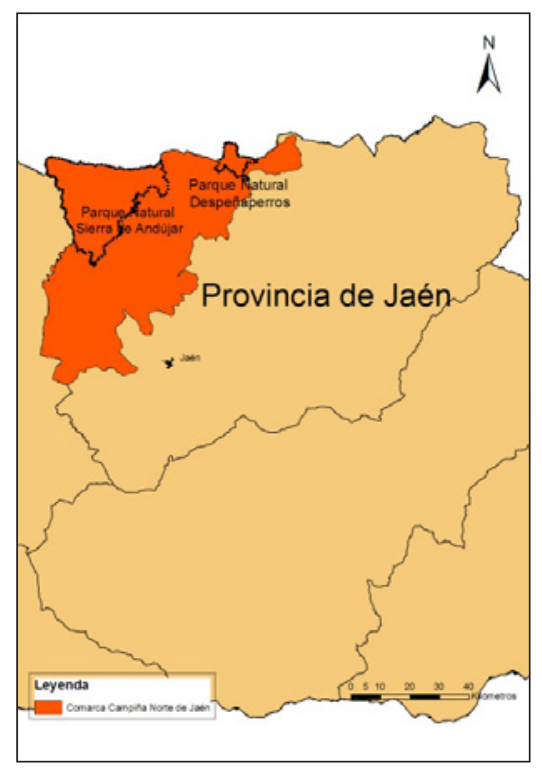

Tales sectores se corresponden con ámbitos serranos bien reconocibles por su alto valor y cualificación ambiental, paisajística y ecológica, lo que se ha vinculado históricamente a unos usos agrarios tradicionales muy extensivos (sobre todo ganaderos y cinegéticos), principalmente ligados a una gran propiedad privada muy preponderante.

La ausencia de una proyección comarcal ha repercutido en la imposibilidad de estrategias turísticas específicas y de carácter integral impulsadas a través de entidades como los GDR (Garzón y Ramírez, 2016), a tenor de la falta de identificación en el referente territorial para la intervención (Figura 9). Los GDR han respaldado proyectos en el ámbito de los parques, si bien de manera puntual y en el marco de iniciativas más amplias, principalmente el Plan Turístico de Sierra Morena (ADIT, 2006).

Otros factores territoriales y administrativos de índole más específica se han contemplado hasta la actualidad como trabas u obstáculos de una posible funcionalización turística.

Entre ellos caben destacar: su baja ocupación humana directa -en forma, por ejemplo, de la recurrente exclusión de los núcleos poblacionales del perímetro de los parques (Figura 10)-; una planificación ambiental básica (PORN y PRUG) que ha otorgado preferencia a la conservación de los valores naturales y paisajísticos -remarcando la necesidad de que funciones como la turística se adapten a ello, principalmente en las Zonas de Reserva y de Protección Especial, superficialmente mayoritarias en estos parques naturales (Consejería de Medio Ambiente 2003/2004)-; y el papel -muy destacado- asumido por la propiedad de la tierra. 
A este respecto, ya se apuntó líneas atrás a la preponderancia de la propiedad privada, en una estructura mayoritaria de extensos predios, que han sustentado grandes explotaciones ganaderas, forestales y, sobre todo, de caza mayor. La propiedad privada ha llegado a alcanzar cotas superiores al $98 \%$ de la superficie en los parques naturales cordobeses (Sierra de Hornachuelos y Sierra de Cardeña y Montoro), siendo algo inferior en la Sierra de Andújar y contando como excepción el Parque Natural de Despeñaperros, área protegida de considerable menor extensión que las anteriores y donde la propiedad pública resulta mayoritaria.

En todo caso, como dinámica general -a los cuatro parques- debe destacarse que la propiedad pública (fundamentalmente autonómica, aunque también en algún caso estatal $^{16} \mathrm{y}$, mucho más puntualmente, municipal) se articula asimismo en grandes fincas, que han venido siendo gestionadas por un concepto que puede calificarse como patrimonial, ya que en su práctica totalidad se han dedicado a trabajos de conservación y mejora biológica (masa vegetal y especies faunísticas amenazadas), excluyendo de manera muy generalizada la posibilidad de acceso y de una proyección -al menos parcial- hacia un uso público-turístico, pese a que en muchos casos tales fincas se localizan en sectores de especial atractivo paisajístico.

Precisamente, el uso público parece conformarse -en la línea que se viene apuntando desde el comienzo de este trabajo- como un factor decisivo para un verdadero impulso turístico de los parques naturales de la Sierra Morena centro-oriental andaluza, más aún a tenor de algunos de los condicionantes territoriales (baja humanización directa, elevada cualificación ecológica y paisajística general, propiedad pública minoritaria y muy localizada en grandes fincas ${ }^{17}, \ldots$ ) ya expuestos para ellos. Habría de tratarse, por tanto, de un uso público necesariamente selectivo y de baja intensidad, pero que al mismo tiempo resultase representativo de los valores territoriales y paisajísticos de estos parques naturales, muy en particular del que acertadamente se ha conceptualizado y caracterizado como paisaje forestal-cinegético (Mulero, 2013).

Sin embargo, tal como puede constatarse mediante la observación de la Figura 10, el uso público ha resultado muy pobre -a nivel de equipamientos y servicios ofertados-, al haberse limitado casi de manera exclusiva a lo que la Estrategia de Acción del uso público en la RENPA (Hernández, 2003) establecía como una dotación de mínimos para cualquier parque natural (centro de visitantes, áreas recreativas y senderos). Pero más allá de la pobre diversificación tipológica -realidad patente también en buena medida en los grandes parques naturales occidentales, como se expuso-, quizá más expresivo de la situación deficitaria del uso público en estas áreas protegidas ha resultado el escaso número de equipamientos acondicionados, además de su extrema polarización territorial (generalmente en el entorno de las principales cabeceras municipales, localizadas en la periferia de los parques), lo que ha repercutido en que amplios sectores de los territorios protegidos hayan quedado completamente al margen de cualquier forma de uso público.

16 Caso de los montes Lugar Nuevo y Contadero-Selladores, en el Parque Natural Sierra de Andújar, de gran peso territorial, ya que ambos suman 19.964 hectáreas de superficie (26,69\% del parque).

17 Además de en los bienes de dominio público (vías pecuarias y dominio público hidráulico), pero cuya disponibilidad para el uso público-turístico resulta escasa en general en estos parques naturales, en función tanto de su localización mayoritaria en zonas de máxima protección (según lo estipulado en la planificación básica) como de su recurrente ocupación ilegal por parte de titulares privados. 
Figura 10

EQUIPAMIENTOS DE USO PÚBLICO DE LOS PARQUES NATURALES SIERRA DE HORNACHUELOS Y SIERRA DE ANDÚJAR SEGÚN SUS PUP
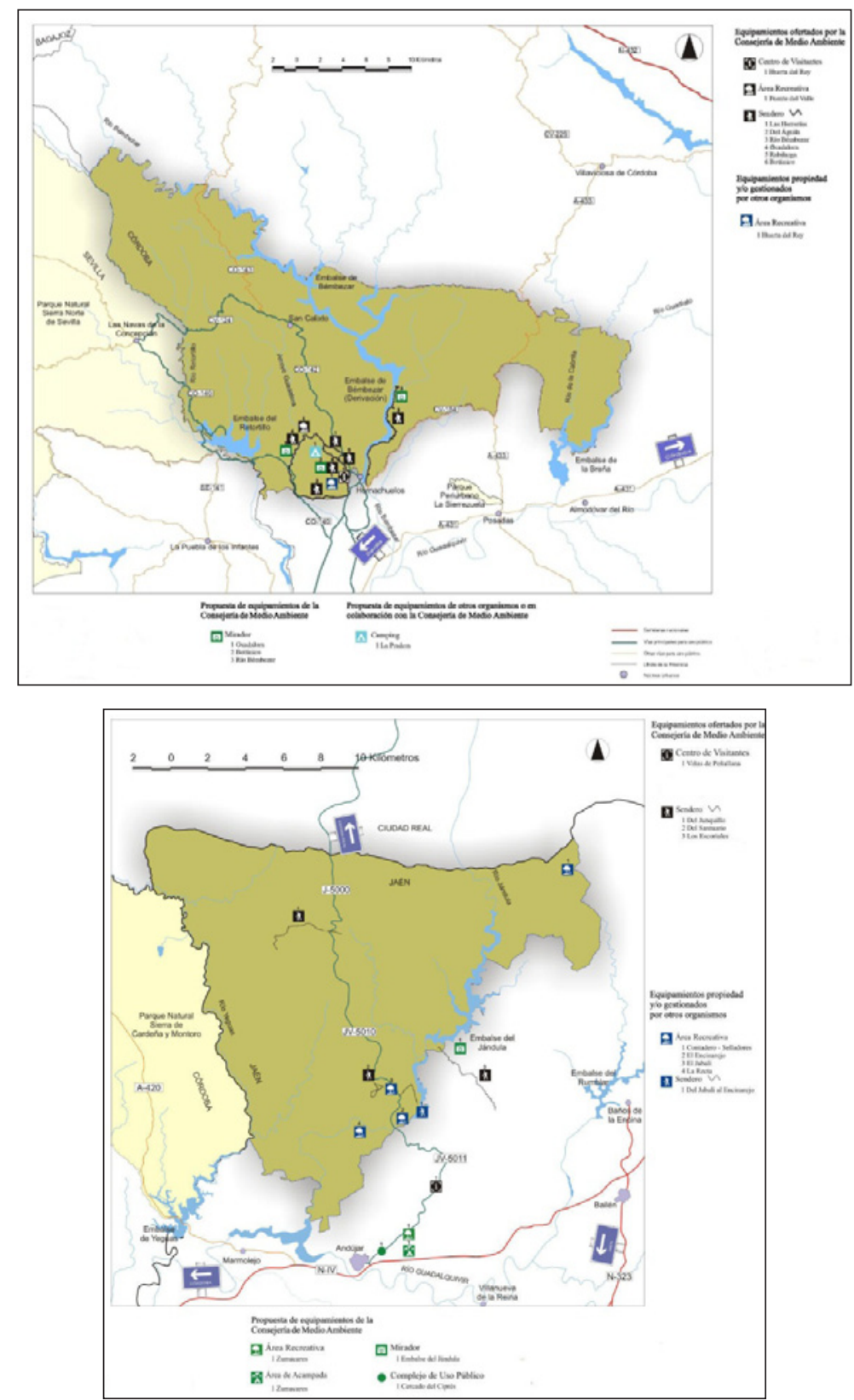

Fuente: Consejería de Medio Ambiente (www.juntadeandalucia.es/medioambiente). 
Han venido resultando, pues, muy limitadas las posibilidades de uso público sobre el terreno, a tenor de una situación de estancamiento de su dotación bastante generalizada y perpetuada en lo esencial hasta la actualidad, lo que ha repercutido en afluencias muy modestas, situadas en todos los casos en el entorno de los 10.000 usuarios anuales (según datos recopilados en los respectivos centros de visitantes), y ceñidas por lo general a una serie muy reducida de equipamientos de mayor atractivo (principalmente senderos, como los de Guadalora y Bembézar, en la Sierra de Hornachuelos, Venta del Charco-Aldea del Cerezo en la Sierra de Cardeña y Montoro, El Encinarejo y El Santuario en la Sierra de Andújar, o Cerro del Castillo en Despeñaperros).

Desde una perspectiva más general, puede afirmarse que los cuatro parques han venido siendo objeto de un modelo de gestión bien reconocible, manifestado en un uso público claramente postergado frente a la conservación biológica (y por ello muy restringido a nivel de su oferta), pese a la teórica compatibilización conservación-uso público definitoria el Parque Natural andaluz, y que explica la formulación y aplicación -en todos los parques, salvo Despeñaperros- de instrumentos como los PUP y la CETS ${ }^{18}$.

En el caso particular de los PUP, estos no fueron renovados -al igual que en los restantes parques naturales andaluces- tras el cumplimiento de su periodo de vigencia, lo que en todo caso se antoja lógico si se considera la no aplicación de las acciones contempladas en ellos para el reforzamiento de la oferta de uso público (Figura 10).

Con todo, y pese a este panorama global, durante los últimos años se han venido registrando ciertas iniciativas interesantes de funcionalización turística en los parques naturales de Sierra Morena centro-oriental, que parecen apuntar a la línea de una efectiva revalorización territorial, en todo caso compatible con la imprescindible conservación de espacios de gran valor y fragilidad ecológica.

Tal ha sido el caso de ciertas actuaciones y proyectos en materia de uso público que, pese a su carácter puntual -al margen de una planificación estable- han adolecido de un alto interés. Entre ellas cabe señalar el acondicionamiento de un observatorio de aves junto al Embalse de Tejoneras (Sierra de Cardeña y Montoro); o la conformación de una red de miradores paisajísticos en carreteras del Parque Natural Sierra de Andújar (Figura 12); o el proyecto -aún no culminado- de reconversión del viejo trazado de la A-4 a su paso por Despeñaperros en vía verde para un uso público-turístico. Se trata, en todos los casos, de intervenciones tipológicamente similares, sustentadas en el aprovechamiento de hitos que permiten disfrutar de los valores ambientales y paisajísticos en contextos territoriales marcados por una fuerte impermeabilidad.

Pero también de intervenciones de índole más propiamente turística, bajo una iniciativa eminentemente privada. Ha destacado la progresiva conformación de un entramado alojativo, aún muy modesto en su dimensión cuantitativa -incluso en el contexto de las respectivas franjas mariánicas provinciales (Figura 11)-, pero con hitos interesantes a nivel de calidad. A este respecto cabe resaltar el acondicionamiento creciente de alojamientos rurales a partir de la revalorización del patrimonio tradicional edificado en medio rústico,

18 Tras los dos grandes parques naturales de la Sierra Morena occidental, el siguiente parque mariánico en ser reconocido fue la Sierra de Cardeña y Montoro, en 2007, renovado en 2012 (con 11 establecimientos adheridos a la CETS a fecha de julio de 2015). Sierra de Andújar y Sierra de Hornachuelos se adhirieron a la CETS en 2009 y 2011 respectivamente, si bien todavía no han renovado la Carta en su Fase II. 
con ejemplos muy significativos, principalmente en antiguas haciendas aceiteras localizadas el entorno más próximo del Parque Natural Sierra de Cardeña y Montoro (Figura 12).

\section{Figura 11 \\ ESTABLECIMIENTOS TURÍSTICOS RURALES EN MUNICIPIOS DE LOS PARQUES NATURALES CORDOBESES Y JIENNENSES}

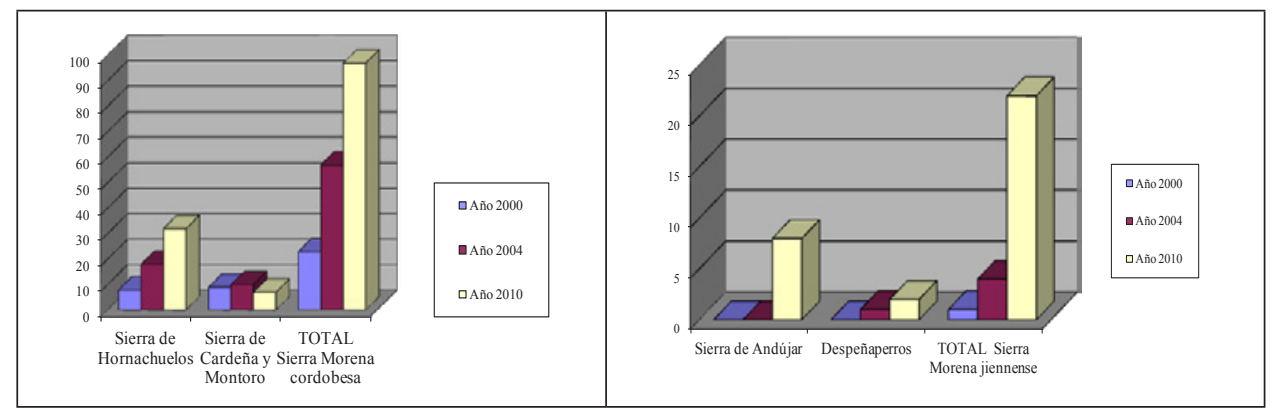

Fuente: Sistema de Información Multiterritorial de Andalucía (SIMA) y Datos Espaciales de Andalucía para Escalas Intermedias (DEA-100). Elaboración propia.

A destacar, asimismo, el surgimiento reciente de un número reducido de empresas de turismo activo, a partir de las nuevas posibilidades de aprovechamiento de hitos de dominio público y de fincas públicas (Figura 12), que comienzan a ser objeto de un incipiente desarrollo turístico, necesariamente puntual, selectivo y de carácter eminentemente educativo (Sánchez, 2001), como se ha venido apuntando.

En una línea similar, debe igualmente remarcarse la creciente regularización manifestada por un sector turístico muy específico, la caza mayor, de gran significación en estos parques naturales cordobeses y jiennenses. De este modo, frente al oscurantismo y elitismo tradicionales de este sector, hoy día se hace patente la proliferación de nuevas empresas de organización y gestión de jornadas cinegéticas, que operan en grandes cotos de los parques naturales, varias de ellas radicadas en municipios de los mismos, destacando sobremanera al respecto el caso de Andújar.

Las nuevas posibilidades turísticas con vinculación al territorio y los recursos de los parques naturales de la Sierra Morena centro-oriental se culminan con la formulación reciente de ciertos instrumentos de planificación turística. Más en concreto han sido dos los aplicados hasta la fecha, ambos en el sector serrano jiennense: la Iniciativa de Turismo Sostenible (ITS) Paisajes Mineros de Jaén y el Plan de Competitividad Turística (PCT) Ruta de los Castillos y Batallas.

Pese al interés de iniciativas como las referidas -concretadas en acciones como, por ejemplo, la construcción del Museo de la Batalla de Las Navas de Tolosa, junto a la localidad de Santa Elena, en la periferia más inmediata del Parque Natural de Despeñaperros (Figura 12)-, lo cierto es que tales iniciativas planificadoras no han mostrado una conexión específica con la realidad Parque Natural, en la línea de una verdadera integración que trascienda del estricto solapamiento territorial y contribuya al efectivo reforzamiento turístico de las áreas protegidas. 


\section{Figura 12}

ALGUNOS HITOS RECIENTES DEL USO PÚBLICO-TURÍSTICO EN PARQUES NATURALES DE SIERRA MORENA CENTRO-ORIENTAL
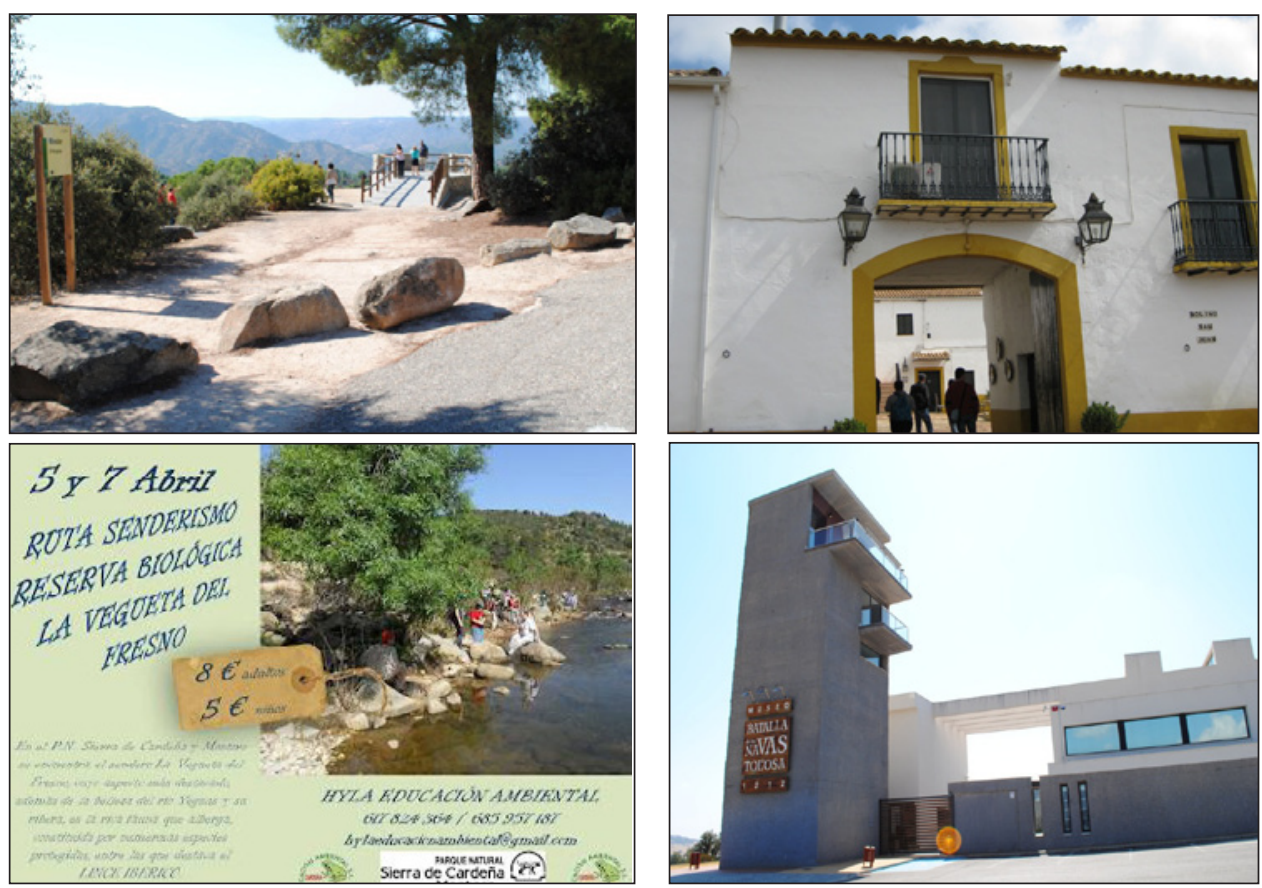

Fuente: elaboración propia.

\section{A MODO DE CONCLUSIÓN: HACIA UNA ESTRATEGIA TURÍSTICA EN LOS PARQUES NATURALES}

En el marco de la creciente percepción -por parte de la demanda- de las áreas protegidas como territorios turísticos, resulta imprescindible la adecuada canalización de dicha funcionalidad. Para ello se antoja ineludible la ponderación de las verdaderas posibilidades de índole territorial al respecto y, sobre esta base, la definición de estrategias de ordenación que permitiesen la conformación de ofertas cualificadas y bien reconocibles para las áreas protegidas, consolidándolas como referentes turísticos per se, a partir de la consideración de los caracteres de diferenciación de cada territorio.

El trabajo desarrollado desde esta perspectiva esencial se ha aplicado a un caso de estudio -el Parque Natural andaluz, en su concreción en los seis espacios así declarados en el macizo de Sierra Morena-, en el que se ha hecho patente con nitidez la ausencia de una estrategia clara y específica para el desarrollo turístico, en su doble dimensión básica de uso público y una oferta de índole más propiamente turística. A este respecto, ha resultado clave la falta de coordinación entre las unidades administrativas responsables de la gestión de las áreas protegidas, de la actividad turística y del desarrollo rural. En relación con este último 
campo de acción, la escasa vinculación específica registrada con carácter global con los territorios sujetos a protección (más allá de la incidencia de las ayudas y subvenciones vinculadas a iniciativas comunitarias como LEADER y FEADER) ha contado con alguna excepción de especial interés, en la línea del papel asumido por ciertos GDR en tanto que dinamizadores de la actividad turística en los parques naturales integrados en sus ámbitos territoriales.

Sea como fuere, el panorama general dibujado ha repercutido de manera directa en la debilidad turística global de la Sierra Morena andaluza -caracterizada ya años atrás por Araque et al. (2005) como un destino en ciernes-, pese a los avances registrados, limitados y desiguales entre parques naturales, resultando un factor decisivo al respecto la proyección comarcal de que se ha dotado a los dos parques de Sierra Morena occidental, frente a sus homólogos del sector centro-oriental del macizo.

En todo caso, pese a tales disparidades, las carencias y desequilibrios internos registrados en todos los parques (más de 25 años después de su declaración) remiten a un fondo común: la apuntada necesidad de una estrategia de ordenación e intervención para cada parque natural, que necesariamente debería superar la recurrente inoperatividad de los mecanismos administrativos aplicados hasta la fecha (sobre todo de los PUP). Dicha estrategia habría de sustentarse, pues, en un instrumento -que bien podría tratarse de la CETS, si bien desde su necesaria reformulación hacia una mayor operatividad- de carácter integral, que considerase al espacio protegido como una realidad turística en sí misma, fijando los fundamentos tanto de la intervención pública (principalmente en materia de uso público) como de la iniciativa privada (con un rol primordial a desempeñar desde los GDR).

\section{BIBLIOGRAFÍA Y OTRAS REFERENCIAS}

ANTÓN CLAVÉ, S., BLAY BOQUÉ, J. y SALVAT SALVAT, J. (2008): “Turismo, actividades recreativas y uso público en los parques naturales. Propuesta para la conservación de los valores naturales ambientales y el desarrollo productivo local". Boletín de la Asociación de Geógrafos Españoles, n 48, pp. 5-38.

ARAQUE JIMÉNEZ, E., CANTARERO QUESADA, J.M., GARRIDO ALMONACID, A., MOYA GARCÍA, E. y SÁNCHEZ MARTÍNEZ, J.D. (2005): "Sierra Morena: una lectura geográfica para un destino turístico en ciernes". Cuadernos de Turismo, $\mathrm{n}^{\mathrm{o}} 16$, pp. 7-48.

BLÁZQUEZ SALOM, M. (2002): “Turismo y ordenación en espacios de interés natural: sinergias y conflictos”. En VV.AA.: Turismo y transformaciones urbanas en el siglo XXI. Almería, Universidad de Almería, pp. 105-117.

CALS GÜELL, J. y RIERA, P. (1989): "La protección de los espacios naturales y su aportación a la oferta turística recreativa". Estudios Turísticos, n ${ }^{\circ}$ 103, pp. 47-84.

CÀNOVES VALIENTE, G., VILLARINO PÉREZ, M. y HERRERA JIMÉNEZ, L. (2006): "Políticas públicas, turismo rural y sostenibilidad: difícil equilibrio". Boletín de la Asociación de Geógrafos Españoles, n 41, pp. 199-220.

CEBALLOS-LASCURAÍN, H. (1996): Tourism, ecotourism and protected areas. Gland, IUCN, $315 \mathrm{pp}$. 
CROSBY, A. y MOREDA, A. (1993): Elementos básicos para un turismo sostenible en áreas naturales. Madrid, Centro Europeo de Formación Ambiental Turística, 141 pp.

EAGLES, P., HAYNES, C. y McCOOL, S. (2002): Turismo sostenible en áreas protegidas: Directrices de planificación y gestión. Madrid, Organización Mundial del Turismo, 183 pp. GARZÓN GARCÍA, R. y ARIAS IBÁÑEZ, E. (2008): “La planificación y ordenación del uso público en espacios protegidos andaluces: contextualización general y estudio específico en el Parque Natural Sierra Norte de Sevilla". Cuadernos de Turismo, $\mathrm{n}^{\circ}$ 21, pp. 33-65.

GARZÓN GARCÍA, R. y RAMÍREZ LÓPEZ, M.L. (2016): “Una reflexión actual sobre la vinculación desarrollo rural-áreas protegidas a partir de la experiencia de la Sierra Morena andaluza”. En RUÍZ PULPÓN, A.R. et al. (Eds.): Treinta Años de Política Agraria Común en España. Agricultura y multifuncionalidad en el contexto de la nueva ruralidad. Ciudad Real, AGE, pp. 366-383.

GÓMEZ-LIMÓN, J. (1993): "El impacto de las actividades recreativas al aire libre sobre los espacios naturales". Quercus, n 90, pp. 18-23.

GRANDE IBARRA, J. (2006): "La evolución del turismo rural en España y las nuevas oportunidades del turismo de naturaleza”. Estudios Turísticos, n ${ }^{\circ}$ 169-170, pp. 85-102.

HERNÁNDEZ DE LA OBRA, J. y GÓMEZ-LIMÓN, J. (2005): Manual sobre conceptos de uso público en los espacios naturales protegidos. Madrid, Fundación Fernando González Bernáldez, 94 pp.

JÁIMEZ GAGO, M.I. (2004): Políticas públicas y turismo. Sevilla, Junta de Andalucía, Consejería de Turismo, Comercio y Deporte, 694 pp.

LÓPEZ OLIVARES, D. (Ed.) (2010): Turismo y gestión de espacios protegidos. XII Congreso Internacional Turismo, Universidad y Empresa. Valencia, Tirant lo Blanch, $723 \mathrm{pp}$.

LUQUE GIL, A. (2003): "Diagnóstico de la capacidad de acogida en alojamientos turísticos en parques naturales andaluces de montaña". Baetica, $\mathrm{n}^{\circ}$ 25, pp. 191-217.

MARCHENA GÓMEZ, M. (1995): "Ideas para la regulación del ocio en los espacios naturales protegidos". En VV.AA.: Propiedad, actividad agraria y medio ambiente en España y América Latina. Actas del VII Coloquio de Geografía Rural. Ponencias y excursiones. Córdoba, Universidad de Córdoba-AGE, pp. 83-108.

MARTÍNEZ ARNÁIZ, M. (2004): "Patrimonio rural y ocio urbano: la banalización del recurso". En VV.AA.: ¿Qué futuro para los espacios rurales? XII Coloquio de Geografía Rural. León, Universidad de León-AGE, pp. 607-615.

MULERO MENDIGORRI, A. (2013): "El paisaje forestal-cinegético en Sierra Morena: una lectura geográfica”. Cuadernos Geográficos, n 52, pp. 108-128.

MULERO MENDIGORRRI, A. y GARZÓN GARCÍA, R. (2005): "Desarrollo rural y espacios naturales protegidos: confusión e ineficacia en torno a los Planes de Desarrollo Sostenible". Ería, no 68, pp. 315-330.

PULIDO FERNÁNDEZ, J. I. (2005): Criterios para una política turística sostenible en los parques naturales de Andalucía. Sevilla, Junta de Andalucía, Consejería de Turismo, Comercio y Deporte, 866 pp. 
PULIDO FERNÁNDEZ, J.I. (2007): “Elementos para orientar la formulación de una política turística sostenible en los parques naturales andaluces". Cuadernos de Turismo, $\mathrm{n}^{\circ} 19$, pp. 167-188.

RIVERA MATEOS, M. (2010): Turismo activo en la naturaleza y espacios de ocio en Andalucía. Aspectos territoriales, políticas públicas y estrategias de planificación. Sevilla, Junta de Andalucía, Consejería de Turismo, Comercio y Deporte. Disponible en http://www.juntadeandalucia.es/turismoycomercio/publicaciones/37957.pdf

ROMERO MACÍAS, E., ROMERO MACÍAS, V. y VARGAS SÁNCHEZ, A. (2011): “El turismo rural y el Parque Natural Sierra de Aracena y Picos de Aroche de la provincia de Huelva (España): una visión de futuro". Pasos, Vol. 9, nº 4, pp. 503-517.

SÁNCHEZ MARTÍNEZ, J.D. (2001): “Turismo rural y sostenibilidad. Consideraciones generales y panorama en los espacios protegidos jiennenses". En CANTARERO QUESADA, J. M. (Coord.): Planificación y gestión del turismo en el medio rural. Úbeda, Centro de Turismo de Interior de Andalucía, pp. 11-32.

SILVA PÉREZ, R. (1994): “Turismo y agricultura en Sierra Morena”. En VV.AA.: Actas del VII Coloquio de Geografía Rural. Córdoba, Universidad de Córdoba-AGE, pp. 446-451.

TROITIÑO VINUESA, M.A. (1995): "Espacios naturales protegidos y desarrollo rural: una relación territorial conflictiva". Boletín de la Asociación de Geógrafos Españoles, $\mathrm{n}^{\circ} 20$, pp. 23-37.

VACAS GUERRERO, T. (2010): "Patrimonio natural: uso público-turístico en los espacios naturales protegidos españoles". Estudios Turísticos, no 186, pp. 69-91.

VALLE BUENESTADO, B. (2001): "Sierra Morena: de espacio agrario a espacio protegido”. En MANERO MIGUEL, F. (Coord.): Espacio natural y dinámicas territoriales. Valladolid, Universidad de Valladolid, pp. 383-396.

VILLARINO PÉREZ, M. et al. (2009): "Reflexiones sobre experiencias de diversificación del turismo rural en España”. Serie Geográfica, n 15, pp. 67-78.

VV.AA. (2008): Turismo en espacios rurales y naturales. Atlas Nacional de España. Madrid, Ministerio de Fomento, Centro Nacional de Información Geográfica, 363 pp.

YUNIS, E. (2006): "Desafíos de la sostenibilidad en turismo. Implicaciones para la conservación de áreas naturales protegidas”. Estudios Turísticos, n 169-170, pp. 77-83.

\section{DOCUMENTACIÓN ADMINISTRATIVA Y NORMATIVA BÁSICA}

ADIT SIERRA MORENA (2006): Plan de Actuación Turística en Sierra Morena. Disponible en www.sierramorena.com

CONSEJERÍA DE CULTURA Y MEDIO AMBIENTE/CONSEJERÍA DE MEDIO AMBIENTE (varios años): Medio Ambiente en Andalucía. Informe. Sevilla, Junta de Andalucía, Consejería de Medio Ambiente.

CONSEJERÍA DE MEDIO AMBIENTE (2003/2004): Planes de Ordenación de los Recursos Naturales y Planes Rectores de Uso y Gestión (Parques Naturales). Sevilla, Junta de Andalucía, Consejería de Medio Ambiente y Ordenación del Territorio. Disponible en www.juntadeandalucia.es/medioambiente 
DIRECCIÓN GENERAL DE TURISMO (1992): Ocio y turismo en los parques naturales andaluces. Sevilla, Junta de Andalucía, Consejería de Economía y Hacienda, Dirección General de Turismo, $216 \mathrm{pp}$.

EUROPARC (1997): Carta Europea de Turismo Sostenible en Espacios Protegidos. Texto Oficial. Federación EUROPARC. Disponible en www.redeuroparc.org

HERNÁNDEZ DE LA OBRA, J. (2003): Gestión del Uso Público en la RENPA. Estrategia de Acción. Sevilla, Junta de Andalucía, 111 pp.

Ley 42/2007, de 13 de diciembre, del Patrimonio Natural y la Biodiversidad.

Ley 2/1989, de 18 de julio, por la que se aprueba el Inventario de Espacios Naturales Protegidos de Andalucía y se establecen medidas adicionales para su protección. 
